\title{
Uma Abordagem Prática com Foco em Gestão de TIC para Ensino de SI para Alunos de Graduação em Computação
}

\author{
Edison Ishikawa ${ }^{1}$, Célia Ghedini Ralha ${ }^{1}$ \\ ${ }^{1}$ Departamento de Ciência da Computação - Instituto de Ciências Exatas - \\ Universidade de Brasília - Campus Universitário Darcy Ribeiro - \\ Caixa Postal 4466 - CEP 70.910-970 - Brasília - DF \\ \{ishikawa, ghedini\}@cic.unb.br
}

\begin{abstract}
Teaching Information Systems (IS) for computer students, with courses very related to Information and Communications Technolgy (ICT) requires adapting the subject with a different approach. This paper presents an approach that exemplifies the application of IS knowledge inside ICT organizations, where evening course learners act, through TIC management IS. The evening course students profile showed that the approch used in the course is well suited to the students reality. The content used and its importance were evaluated applying a questionnaire to the evening course students. Responses showed that this approach increased students' IS subject understanding and the desire to apply IS knowledge in theirs professional activities.
\end{abstract}

Resumo. Ensinar a disciplina de Sistemas de Informação (SI) para alunos graduandos dos cursos de computação (licenciatura, bacharelado e engenharia) ligados à Tecnologia da Informação e Comunicações (TIC) exige uma adaptação na forma de abordar o conteúdo programático da disciplina de SI. Este artigo apresenta uma abordagem prática que exemplifica a aplicação do conhecimento adquirido com o estudo do conteúdo programático da disciplina de SI em organizações de TIC, onde os discentes do turno noturno atuam, por meio de SI de gestão de TIC. O levantamento do perfil dos alunos do turno noturno permitiu verificar que a abordagem adotada se adequa à realidade dos alunos. O conteúdo programático e sua importância foram avaliados aplicando-se um questionário aos alunos do turno noturno. As respostas revelaram que a abordagem de ensino adotada aumentou a compreensão dos alunos sobre SI e a motivação para aplicar este conhecimento nas atividades profissionais.

\section{Introdução}

A abordagem usual de ensino de Sistemas de Informação (SI), baseada nos conteúdos dos principais livros da área [Laudon 2015, Rainer 2008, M. Stair 2006], cujo público alvo são alunos e profissionais da área de administração e gestão de negócios, que precisam conhecer os conceitos de Tecnologia da Informação e Comunicações (TIC) de forma abrangente para gerir e tornar a sua organização competitiva, não cobre as necessidades de conhecimento específicas dos alunos graduandos dos cursos de Computação. Além disso, a abordagem empregada nos cursos de graduação em SI, onde os conceitos relacionados a SI são vistos em maior profundidade em várias disciplinas [SBC 1999], possui conteúdo

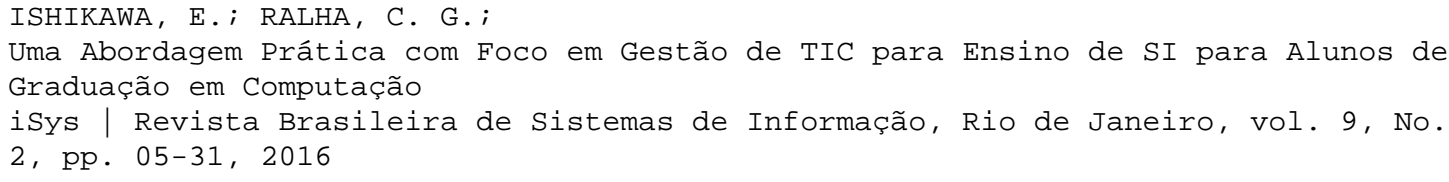


programático extenso para ser ministrada em uma única disciplina de SI. Devido a estes fatos, a disciplina SI destinada a estudantes dos cursos de Computação precisa ter uma abordagem distinta, para não se tornar repetitiva ou por demais desmotivadora aos alunos que tem grande envolvimento com a área de TIC.

Neste contexto, este trabalho propõe a adoção de uma abordagem teórico/prática compatível com as necessidades dos cursos de Computação, em que os alunos implementam soluções, desenvolvendo SI dentro de uma organização real, ao mesmo tempo que aprendem como o negócio de TIC a permeia. A adoção de uma abordagem prática, implementando-se soluções baseadas na realidade, em simuladores ou jogos, como demonstrado por vários autores, melhora a aprendizagem dos alunos [França et al. 2015, Gestal 2014, Nogueira et al. 2013, Suzuki et al. 2011, Rebouças et al. 2010].

Para alcançar os objetivos propostos, os alunos são incentivados a desenvolver SI que pertencem à atividade fim de TIC na organização, ou seja, o domínio de negócio ou conhecimento a ser modelado e implementado é da própria TIC. Alguns alunos desenvolvem SI que usam a TIC como um meio, ou seja SI de gestão de negócios que não tem TIC como atividade fim. Esta abertura é útil para que os alunos vejam exemplos de outros tipos de SI e aprendam com a experiência que as outras equipes vivenciaram.

Por este enfoque, é possível perceber que a ênfase será preparar o profissional para atuar no setor de TIC de uma organização, ou também em uma organização cuja atividade fim seja a TIC ou tenha foco em TIC, como a Amazon, o Google, o Netflix, ou os prestadores de serviços de telecomunicações como GVT, VIVO, Sky, ou mesmo organizações públicas de TIC como o SERPRO, a DATAPREV, entre outras.

Esta abordagem de ensino de SI para cursos de Computação procura preencher a lacuna que existe em relação aos SI do domínio de negócio que tem a TIC como atividade fim, nos níveis operacional, de conhecimento, gerencial e estratégico de uma organização. A abordagem prática foi inicialmente aplicada à turma de SI do segundo semestre de 2014 do turno noturno da Universidade de Brasília $(\mathrm{UnB})$ com turmas de até trinta e cinco alunos. Inicialmente levantou-se o perfil dos alunos para se comprovar algo já conhecido informalmente, a de que a maioria de seus alunos exercem atividade laborais no período diurno, muitos deles na área de TIC, razão pela qual esta abordagem foi elaborada. NO final do semestre foi aplicado um questionário sobre os conteúdos específicos de SI e de TIC, sendo seus resultados avaliados.

O restante deste documento está dividido da seguinte forma: Na Seção 2 são apresentados os trabalhos da área, mostrando a existência de um trabalho relacionado. Na Seção 3 descreve-se a metodologia de pesquisa. Na Seção 4 é apresentada a proposta prática de ensino. Na Seção 5 está ilustrada a proposta com alguns trabalhos realizados pelos alunos da disciplina SI nos cursos de Computação. Na Seção 6 apresenta-se o perfil dos discentes da disciplina. Na Seção 7 são apresentados os resultados da pesquisa sobre o conteúdo da disciplina SI realizada no final do período. Por fim, na Seção 8 são apresentadas as conclusões e trabalhos futuros.

\section{Trabalhos Relacionados}

Para o levantamento dos trabalhos relacionados foi realizada uma revisão sistemática com uma metodologia explícita passível de reprodução [Sampaio 2007]. O objetivo desta revisão foi compilar os trabalhos relacionados ao ensino da disciplina de SI para alunos 
de graduação da área de Computação. Para atingir este objetivo, foi utilizada a base de dados eletrônica do Google Scholar [Scholar 2016]. O Google Scholar indexa artigos publicados pela Elsevier, ACM, IEEE, JSTOR, Springer, Wiley Online Library, Morgan Kaufmann, Sagepub, MIT Press, seer.unirio.br, entre outras editoras.

A busca foi realizada com palavras-chave em inglês e português. A busca na língua inglesa foi realizada com as seguintes palavras-chave: "information systems", discipline, “computer science”, ict, teaching, e undergraduate obtendo-se 11440 trabalhos, ordenados por relevância. Como o universo de trabalhos a ser analisado continuava muito grande, a busca foi refinada excluindo-se as seguintes palavras-chave: gis, erp, "information literacy", "information science", "distance learning”, "distance education", " $e$ learning”, "blended learning”, gender, ethic, health, medical e security, obtendo-se 398 trabalhos.

A busca na língua portuguesa foi realizada com as seguintes palavras-chave: "sistemas de informação" combinada com ensino, disciplina, tecnologia, graduação computação, obtendo-se 6930 resultados ordenados pela relevância. Para refinar a busca excluiu-se as palavras-chave: programação, saúde, "ciência da informação", matemática, programação, contábeis, geográficas, $\mathrm{EaD}, \mathrm{IHC}$ e distância. Como resultado obteve-se um total de 171 trabalhos.

Os títulos e os resumos dos trabalhos retornados pelo mecanismo de busca do Google Scholar foram analisados, classificados e sumarizados na Tabela 1.

Tabela 1. Classificação dos trabalhos da revisão sistemática

\begin{tabular}{|c|l|c|c|}
\hline Tema & Classificação & Inglês & Português \\
\hline 1 & Ensino da disciplina de SI para estudantes de computação & 0 & 1 \\
\hline 2 & SI - área acadêmica de ensino, pesquisa e extensão & 9 & 2 \\
\hline 3 & SI - disciplina para cursos de administração e outros & 7 & 1 \\
\hline 4 & SI - cursos de graduação & 16 & 6 \\
\hline 5 & SI - cursos de pós-graduação & 4 & 1 \\
\hline 6 & Educação de professores de computação & 8 & 2 \\
\hline 7 & Ensino para estudantes de computação & 26 & 17 \\
\hline 8 & Ensino de computação para estudantes em geral & 37 & 2 \\
\hline 9 & Informática na Educação & 41 & 14 \\
\hline 10 & Outros & 250 & 125 \\
\hline & Total & 398 & 171 \\
\hline
\end{tabular}

Após a análise dos resultados, optou-se por classificar os trabalhos em dez temas para melhor caracterizar a escassez de trabalhos relacionados a este artigo. O Tema 1 - Ensino da disciplina de SI para estudantes de computação, enquadra os trabalhos que abordam o ensino da disciplina de SI para alunos de graduação da área de Computação. O presente artigo se enquadra neste tópico. Apesar dos autores considerarem esta temática importante, encontrou-se apenas um artigo em português sobre o ensino da disciplina de SI para alunos de computação e nenhum em inglês. [Ralha 2006] apresenta a iniciativa de incorporar à disciplina de SI uma proposta de programa de ensino de SI para alunos de graduação da área de computação baseado na integração de fundamentos básicos de sistemas, modelagem de processos e o uso do modelo ITIL, revelando um pioneirismo ao 
incorporar um SI típico da área operacional de TIC de uma organização no conteúdo da disciplina. Neste sentido, o trabalho de [Ralha 2006] foi o precursor deste, uma vez que este trabalho aborda SI da área de TIC que incluem não só ITIL, mas a Gestão de Serviços de TI, Governança de TI, e outros SI comuns à área de Gestão de TIC.

Para melhor caracterizar a lacuna de trabalhos específicos de ensino de SI para estudantes de computação, os demais trabalhos analisados que não se enquadravam neste tema foram classificados da seguinte forma:

- Tema 2: SI - área acadêmica de ensino, pesquisa e extensão - trabalhos que tratam de SI como uma área de conhecimento própria;

- Tema 3: SI - disciplina para cursos de administração e outros - trabalhos que tratam do ensino da disciplina SI no contexto de cursos de graduação em administração, contabilidade, economia, finanças, entre outras áreas de Ciências Sociais Aplicadas;

- Tema 4: SI - cursos de graduação - trabalhos que tratam o ensino em cursos de graduação em SI;

- Tema 5: SI - cursos de pós-graduação - trabalhos que tratam o ensino em cursos de pós-graduação em SI;

- Tema 6: Educação de professores de computação - trabalhos que tratam da formação, capacitação ou avaliação de professores de computação;

- Tema 7: Ensino para estudantes de computação - trabalhos que envolvem metodologias, técnicas de ensino, empreendedorismo, estágios e projetos de graduação para alunos da área de Computação;

- Tema 8: Ensino de computação para estudantes em geral - trabalhos que envolvem metodologias, técnicas de ensino, empreendedorismo, estágios e projetos de graduação com o uso da computação;

- Tema 9: Informática na Educação - trabalhos sobre o uso da TIC na educação; e

- Tema 10: Outros - trabalhos que não se enquadraram nos temas anteriores, como propostas de novos SI, SI para turismo, SI de jornalismo e SI aplicado a diferentes domínios.

Do exposto, é possv́el perceber que o tema Ensino da disciplina de SI para estudantes de computação é um assunto em que existe escassa literatura a respeito.

\section{Metodologia de Pesquisa}

O presente trabalho apresenta uma abordagem prática para o ensino do conteúdo programático da disciplina de SI. Em relação ao objeto de estudo, esta pesquisa se classifica como prescritiva, uma vez que detalha não apenas a descrição da abordagem utilizada, mas propõe uma solução ao caso estudado.

Também se enquadra na classificação de pesquisa qualitativa, uma vez que não tem por objetivo coletar números, mas entender a percepção dos alunos em relação à disciplina de SI. É uma pesquisa experimental de campo, uma vez que a abordagem proposta foi aplicada na disciplina de SI, com posterior avaliação por meio da aplicação de questionário aos alunos de SI do turno noturno.

A operacionalização metodológica da pesquisa foi iniciada com uma exploração dos conteúdos usualmente abordado na disciplina de SI. Basicamente consultou-se os livros textos de SI disponíveis no mercado brasileiro. Verificou-se que a totalidade 
dos títulos eram voltados para alunos dos cursos de administração e eram traduções de títulos norte-americanos. Analisou-se também as diretrizes curriculares para cursos de computação da SBC [SBC 1999], particularmente em relação ao detalhamento das matérias do currículo de referência. Em seguida avaliou-se a abordagem utilizada na disciplina de SI desde 2004 [Ralha 2006] e notou-se que era necessária a sua atualização. Desta forma, a presente abordagem de ensino de SI é uma evolução da abordagem iniciada em 2004 nesta instituição de ensino.

Com o objetivo de se avaliar a adequação da abordagem proposta, inicialmente foi realizado o levantamento do perfil dos alunos do curso noturno do segundo semestre de 2014, ano em que esta abordagem foi implementada, para levantar dados sobre as atividades laborais dos alunos do turno diurno, entre outros dados. Ao final da disciplina foram aplicados aos alunos do turno noturno questionário referentes ao conteúdo da disciplina de SI, para avaliar a adequação da abordagem. Como a abordagem prática para o ensino de SI se mostrou adequado ao perfil dos alunos, não houve a necessidade de aplicar o questionário nas turmas subsequentes. No entanto, o levantamento do perfil dos alunos continuou sendo realizado, para verificar a regularidade no perfil da turma.

\section{Proposta de Ensino}

O objetivo da abordagem de ensino adotada é permitir que os alunos entendam como pessoas podem criar valor pelo uso da informação e como isto pode ser melhorado, com uma abordagem de ensino mais prática do que teórica. O aluno tem que pensar estrategicamente de forma a considerar como os tomadores de decisão podem usar a informação para criar valor, ou seja, viabilizando a inovação. Para isto, o aluno precisa aprender a pensar em como projetar, criar ou adaptar SI que criem este valor [Nunamaker 1990].

Para que os alunos ajam de forma criativa e inovadora, os alunos dos cursos de computação usam como estudo de caso problemas da área de gerenciamento de informações de TIC, sendo incentivados a aplicar, onde for possível, inovações tecnológicas que podem mudar radicalmente o domínio de negócio da empresa. Concomitantemente, aprendem como SI inovadores podem mudar o paradigma do modelo de negócios da empresa de forma que ela continue competitiva.

Em termos de estrutura organizacional onde os SI estão inseridos é apresentado uma pirâmide estendida pelos autores, como mostra a Figura 1. Esta pirâmide, além da estrutura organizacional tradicional dividida em níveis de forma horizontal (níveis operacional, de conhecimento, gerencial e estratégico) ela também é dividida verticalmente de forma funcional (vendas e marketing, manufatura e produção, finanças e contabilidade e recursos humanos). O interessante nesta pirâmide é o acréscimo de mais uma dimensão que permeia toda a organização, explicitando claramente o uso da TIC em todos os níveis e funções da empresa.

Salientamos que a dimensão de TIC que permeia a organização, pode estar distribuída pelos diversos níveis decisórios da organização, ou mesmo centralizado em uma única unidade, por exemplo, superintendência, diretoria, ou departamento de TIC. Além disso, a área de TIC pode ser estruturada em níveis decisórios análogos aos existentes nos níveis hierárquicos da empresa. Outro ponto ressaltado na disciplina, é que esta unidade de TIC pode ter muita informação a ser gerenciada, que seus processos também permeiam a empresa e, portanto, seria interessante que os SI fossem integrados e, de preferência, 


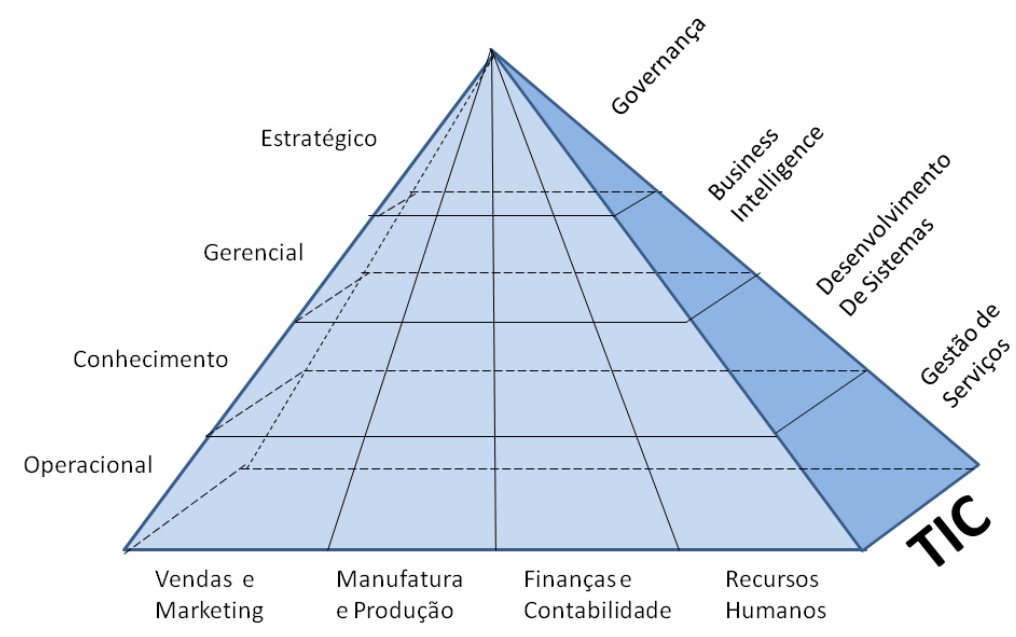

Figura 1. Estrutura organizacional com a dimensão (visão dos autores).

unificados para diminuir custos.

Além disso, a disciplina SI dos cursos da área de Computação tem o papel importante de relacionar as diversas outras disciplinas de Ciência de Computação dentro da subárea de Metodologias e Técnicas de Computação: Engenharia de Software, Banco de Dados, Linguagens de Programação e Processamento Gráfico [CNPQ 2015]. Para isso, esta proposta procura fazer com que os alunos aprendam estes conhecimentos na prática, usando-os na implementação de um SI, algo semelhante a um hackthon ${ }^{1}$ [Grijpink 2015, The Economist 2015].

\subsection{Justificativa}

Os alunos da disciplina SI dos cursos da área de computação já conhecem ou irão conhecer a TIC e necessitam complementar este conhecimento com a sua aplicação em organizações públicas ou privadas, agregando conhecimentos de Administração de Negócios, Teoria Geral de Sistemas, Gerenciamento de Projetos, entre outros.

A implementação de SI que resolvem, na prática, os problemas que os alunos irão enfrentar como profissionais da área de TIC é importante para motivar os alunos não só em relação à disciplina, mas ao seu curso de graduação, mostrando de forma direta a aplicação de SI na área de TIC. Também atua com efeito colateral de diminuir a evasão existentes nos cursos de graduação [Silva Filho 2007].

Esta abordagem permite que o aluno também possa estudar, analisar, compreender e aperfeiçoar os processos organizacionais de TIC que permeiam a organização e aplicálos na sua carreira profissional.

\footnotetext{
${ }^{1}$ Evento em que programadores colaboram intensivamente para o desenvovimento de projetos de software
} 


\subsection{Detalhamento da Proposta}

Como roteiro da disciplina, os alunos estudam os níveis organizacionais de um setor de TIC e propõe um SI da área de TIC para ser projetado e implementado. Nesta proposta, os alunos recebem a recomendação de que os SI a serem implementados devem estar distribuídos entre os diversos níveis organizacionais de um setor de TIC. Por exemplo, se as propostas se concentrarem no nível operacional, as piores propostas serão reprovadas e os alunos teriam que apresentar novas propostas que devem ser SI de outros níveis organizacionais. Esta recomendação se justifica uma vez que cada turma de SI funciona como um laboratório experimental de projetos, onde os alunos devem ter uma visão integrada dos diversos desafios correspondentes aos níveis organizacionais de TIC.

Após a definição do sistema a ser projetado e implementado, as equipes realizam um levantamento das necessidades de gestão da informação e inovação do sistema e elicitam os requisitos funcionais e não funcionais. Durante o levantamento das necessidades e elicitação dos requisitos é esclarecido aos alunos que requisitos que são muito restritivos podem, ao invés de melhorar a especificação, inibir a inovação. Por exemplo, especificar que o sistema deve utilizar uma determinada tecnologia, sem que esta tecnologia seja mandatária devido a decisões de padronização da empresa pode conduzir a uma solução limitada por esta escolha antecipada. Inibem a inovação por que estão antecipando uma solução, que pode não ser a melhor.

Após o levantamento dos requisitos, os alunos modelam o sistema utilizando UML na ferramenta Astah [Astah 2015] e analisam os processos utilizando Business Process Management Notation (BPMN) com a ferramenta Bizagi [Bizagi 2015]. A implementação do protótipo, é feita de preferência em uma nuvem computacional, utilizando um Sistema de Gerenciamento de Banco de Dados (SGBD) e uma linguagem de programação para implemtação da aplicação, sendo que a infreaestrutura computacional, o SGBD e a linguagem de programação são de livre escolha da equipe, visando a solução do problema. Ou seja, procura-se aproveitar a motivação existente em competições de programação [Digiampietri et al. 2012] como um hackthon, mas de forma mais sistematizada, com uso de metodologia de documentação e com a duração de um semestre letivo. No final do período os alunos apresentam seus trabalhos para toda a turma.

Para agregar o conhecimento de gestão com a TIC, o Business Process Management (BPM) foi utilizado [Ralha 2006], com foco no papel do analista de negócios na melhoria dos processos da organização, na necessidade de se integrar os diversos SI da organização, gestão de processos por indicadores, Balanced Score Card (BSC) e gestão com base em evidências (dados e fatos) de acordo com os critérios de Excelência da Fundação Nacional da Qualidade (FNQ) e do IAGP- Instrumento de Avaliação da Gestão Pública (específico para empresas públicas).

Para um aluno de um curso de computação, é fundamental que ele visualize como a organização funciona, como a TIC a permeia (uma vez que o aluno pode estar inserido no mercado de trabalho) e, principalmente, como são os SI da organização. Com esta finalidade, a classificação dos SI de TIC de acordo com os níveis de tomada de decisão hierárquica da organização será apresentada na sequência. 


\subsubsection{Nível Operacional}

Neste ponto é apresentado ao aluno a unidade de TIC que realiza os serviços diários que mantém a infraestrutura de TIC de uma organização. $\mathrm{O}$ atendimento aos pedidos de manutenção dos computadores, da rede que não está conectada à Internet, do telefone VoIP (Voice over IP) que está mudo, da substituição do tonner da impressora que está no fim, entre outros incidentes. É explicado que o ideal é que estes serviços estejam integrados com os demais sistemas dos outros departamentos da organização. Por exemplo, a necessidade da troca do cartucho de tonner da impressora pode gerar um pedido de compra para o Departamento de Compras. Também é mostrado que estes serviços de TIC precisam ser gerenciados de forma adequada, para que os usuários tenham um serviço de qualidade e para que a TIC contribua com a organização na sua missão negocial. Ou seja, que neste nível os SI devem prover ao gerente de TIC a capacidade de acompanhar as atividades e transações elementares de serviços da organização, e que caso a Gestão dos Serviços de TIC seja grande e complexa ele pode recorrer a uma biblioteca com as melhores práticas, como a ITIL (Information Technology Infrastructure Libray)[OGC 2011] ou o MOF (Microsoft Operations Framework) [Microsoft 2008].

\subsubsection{Nível de Conhecimento}

Neste nível organizacional ficam os responsáveis pelo desenvolvimento de soluções de software e hardware da empresa. Aqui a empresa integra novos conhecimentos nos negócios e auxilia a organização a controlar o fluxo de informações. Ou seja, é onde os programadores, analistas de sistemas e cientistas de computação trabalham. Eles não só agregam novos conhecimentos do negócio nos SI da empresa, mas também as viabilizam usando novas tecnologias no seu desenvolvimento. Por exemplo, para que os SI possam ser acessados pela Internet, medidas de segurança deverão ser implementadas utilizando, por exemplo, o padrão Open Web Application Security Project (OWASP) [OWASP 2008]. Para que o sistema seja escalável, ele pode ser implementado em nuvem [Buyya et al. 2009]. Para mapear e otimizar os processos automatizados pelo sistema os alunos utilizam as técnicas do BPM [Pavani 2011].

\subsubsection{Nível Gerencial}

Neste nível organizacional os dados provenientes do nível operacional são consolidados em relatórios periódicos, os quais servem para os gerentes monitorarem, controlarem e tomarem decisões no setor de TIC. Que neste nível, sobre os dados produzidos pelos SI do nível operacional podem ser aplicadas técnicas de Inteligência de Negócios (BIBusiness Intelligence) para realizar inferências, para definir estratégias de competividade [Barbieri 2011]. Que para as informações obtidas por relatórios e BI serem válidas, os dados advindos dos SI de nível operacional precisam ter qualidade, e que para isso é preciso governança sobre os dados. 


\subsubsection{Nível Estratégico}

Neste nível organizacional são realizados os planejamentos de longo prazo. Ou seja, a alta direção da empresa necessita estabelecer uma Governança de TIC eficaz, para que ela garanta a criação de valor para os negócios da empresa, para que se crie uma cultura de TIC que preserve seus investimentos.

Para isso, os alunos precisam perceber que a TIC é um dos principais ativos de uma empresa, junto com os recursos humanos, físicos, financeiros, de propriedade intelectual e de relacionamentos e que o responsável pela área de TIC precisa sensibilizar e conscientizar a alta direção da empresa para a importância de se ter uma governança de TIC bem definida. Mais do que isso, ele tem que ser o parceiro da alta direção da empresa ou do negócio, que geralmente entendem pouco de TIC, apesar de precisarem de TIC e muitas vezes se sentirem frustrados com o retorno de investimento (return on investment - ROI)

Os altos dirigentes veem que existe uma desconexão entre o negócio real e o que a TIC está fazendo. Ou seja, que eles (os atuais alunos dos cursos de computação e futuros profissionais de TIC) também precisam entender do negócio para poderem conversar par-a-par com a alta administração da empresa, para juntos poderem extrair benefícios estratégicos crescentes [Weill 2004].

Dentro deste contexto, a abordagem de ensino prática adotada mostra ao aluno que a TIC, atualmente, é parte essencial para a competitividade do negócio, e que, a forma profissional de alinhar os objetivos de negócios aos objetivos de TIC é por meio de uma Governança de TIC profissional e de qualidade.

Os assuntos básicos de Governança de TIC que uma empresa precisa ter são introduzidos pela definição dos princípios de TIC, que são declarações claras, de alto nível, sobre como a TIC é utilizada no negócio. Para maior compreensão dos alunos, são mostradas regras de governança que, por exemplo, uma empresa tenha adotada e sua alta direção mostre firme vontade de que elas sejam cumpridas, como: "As soluções de TIC devem se basear em padrões de mercado, utilizando sempre que possível soluções abertas", ou "Todos na empresa devem se preocupar com a corretude dos dados inseridos nos SI da empresa, de forma a assegurar a corretude dos relatórios gerenciais e a validade das informações obtidas por meio de softwares de Business Intelligence". Desta maneira, os alunos sem muita experiência em gestão de TIC entendem o que é governança e o que são as melhores práticas de governança de TIC preconizadas pelo Control Objectives for Information and Related Technology (COBIT) [Audit and Association 2015].

\subsection{Contexto e Aplicação da Proposta}

$\mathrm{Na}$ UnB, a disciplina de SI é obrigatória para os cursos de Licenciatura em Computação (noturno) e Bacharelado em Ciência da Computação (diurno), sendo optativa para os cursos diurnos de Engenharia de Computação e Mecatrônica, além de poderem ser cursadas como módulo livre pelos alunos dos demais cursos de graduação. Os alunos dos diversos cursos de computação podem escolher o turno que preferem cursar SI, tendo a mesma carga horária de 60 horas por semestre, correspondendo a 4 créditos, com 4 horas/aula semanais, durante um semestre letivo que varia de 16 a 18 semanas.

Os alunos da licenciatura e do bacharelado podem cursar a disciplina a par- 
tir do quarto período, tendo como pré-requisitos a disciplina de estrutura de dados ou programação sistemática. Semestralmente são oferecidas duas turmas com 30 a 40 alunos em ambos os turnos. A disciplina SI do turno diurno e noturno possui o mesmo conteúdo programático, diferindo na duração da hora/aula, 55 e 50 minutos, respectivamente, e dos professores que a ministram. Outra característia que parece óbvia, comprovado no levantamento do perfil dos alunos de SI do turno noturno, é que os mesmos, em sua maior parte exercem alguma atividade econômica no turno diurno. Isto lhes confere uma experência prática prévia de como funciona a administração de uma organização, o que torna o universo dos alunos do turno noturno distinto dos alunos do turno diurno. Esta pesquisa focou o universo dos alunos do turno diurno.

\subsubsection{Ementa e Programa Básico}

O objetivo da disciplina de SI é preparar o aluno para trabalhar com sistemas computacionais nas dimensões tecnológica, organizacional e humana, através da visão sóciotécnica. O foco de atenção da disciplina está na automação dos processos de negócio nas organizações, de maneira a racionalizar o uso de recursos e melhorar o processo de tomada de decisão, o controle de custos e a qualidade dos negócios realizados no âmbito organizacional. Para atingir estes objetivos, a disciplina é dividida em quatro módulos:

\section{Módulo 1}

Fundamentos de SI. Conceitos básicos (dados, informação, conhecimento). Fundamentos de Teoria Geral de Sistemas. Abordagem sistêmica das organizações. Tipos de SI.

\section{Módulo 2}

Processos de Negócio. Modelagem de processos de negócio. Implementação de processos de negócio. Gerência de processos de negócio.

\section{Módulo 3}

Tecnologia da Informação e Comunicações (TIC). Recursos de TIC. Gestão de serviços de TIC. Governança de TIC.

\section{Módulo 4}

Aplicações. Noções de Análise e Projeto de Sistemas com Orientação a Objetos (UML e RUP). Noções de Projeto e Modelagem de Banco de Dados. Implementação de um protótipo de SI. 


\subsubsection{Instrumentos de Avaliação}

A avaliação consiste de 4 (quatro) trabalhos práticos. O primeiro trabalho é a definição do sistema a ser desenvolvido, seu escopo e o levantamento de seus requisitos. O segundo trabalho consiste na modelagem do sistema especificado no primeiro trabalho usando BPMN [Group 2015] e UML [Podeswa 2009]. O terceiro trabalho é a implementação do sistema definido no primeiro trabalho e modelado no segundo trabalho. O quarto trabalho é um artigo científico sobre o trabalho desenvolvido e a apresentação do artigo para a classe.

Além do trabalho, são aplicadas 02 (duas) provas individuais sem consulta, sendo que a primeira prova com o conteúdo dos módulos I e II e a segunda com o conteúdo dos módulos III e IV. Complementando a avaliação, os alunos realizam seminários apresentados e discutidos em classe, sobre assuntos atuais de TIC, como Computação Verde e suas implicações nas organizações, impressores 3D e como estas tecnologias podem afetar os negócios nas organizações.

\section{Exemplos de Trabalhos}

Para exemplificar alguns dos resultados da aplicação desta metodologia, seguem quatro trabalhos realizados por alunos da disciplina SI do turno noturno no período de 2014 a 2015. Para a realização dos trabalhos os alunos seguiram o ciclo de vida para o desenvolvimento de sistemas preconizado pelo RUP [Kroll 2003], incluindo modelagem UML e do processo de negócios em BPMN. O trabalho é divido em 4 fases, como visto anteriormente na subseção Instrumentos de Avaliação, detalhados a seguir. Em cada fase, a equipe de alunos precisa entregar um artefato ou protótipo do sistema.

Na Fase 1 o artefato é um documento contendo a visão geral do sistema a ser desenvolvido, um estudo para verificar outros SI semelhantes ao escolhido, a justificativa de se investir no seu desenvolvimento, o escopo do sistema e seus requisitos funcionais e não funcionais. Este documento é entregue por meio do site de Ensino a Distância (EaD) Moodle [Moodle 2016] até a quarta semana de aula e o professor solicita esclarecimentos aos alunos do que não está claro no documento e retorna as críticas e sugestões ao trabalho.

Na Fase 2 o artefato é um documento com a modelagem do sistema. A modelagem inclui o mapeamento dos processos $A S-I S$ e $T O-B E$ utilizando a notação BPMN utilizando a ferramenta Bizagi [Bizagi 2015] e os documentos da modelagem de sistemas em UML, utilizando a ferramenta Astah [Astah 2015]. A este artefato, os alunos devem agregar o conteúdo do artefato da Fase 1 com possíveis alterações, se for o caso. Este documento é entregue por meio do site de EaD até a nona semana de aula. Da mesma forma, o professor solicita esclarecimentos aos alunos do que não está claro no documento e retorna as críticas e sugestões ao trabalho.

Na Fase 3 os alunos apresentam o sistema definido na Fase 1 e modelado na Fase 2, juntamente com o artefato da Fase 3 que é um texto documentando os detalhes do desenvolvimento do sistema. O protótipo é apresentado e o artefato é entregue por meio do site de $\mathrm{EaD}$ até a décima terceira semana de aula. Da mesma forma, o professor solicita esclarecimentos aos alunos do que não está claro no documento e retorna as críticas e sugestões ao trabalho. 
Por fim, na Fase 4, os alunos escrevem um artigo sobre o trabalho implementado (utilizando o formato da Sociedade Brasileira de Computação) sobre o trabalho desenvolvido com uma comparação dele com sistemas semelhantes, no que ele é diferente ou inovador em relação ao que já existe, a justificativa do seu desenvolvimento, a modelagem do SI, as plataformas e ferramentas utilizadas no seu desenvolvimento, descreve o sistema resultante e uma conclusão que inclui trabalhos futuros. Este artigo também é entregue por meio do site de EaD até a décima quinta semana de aula. Além do artigo entregue por meio do Moodle, a equipe faz uma apresentação do trabalho para a classe na décima sexta semana de aula.

Apesar do curto espaço de tempo para a realização dos trabalhos, em média dezessete semanas de aula, os alunos de SI do turno noturno apresentaram trabalhos simples, adequados para uma disciplina do quarto período da graduação, mas que cumpriram com os objetivos da disciplina SI. Ou seja, ao realizar os trabalhos os alunos lidaram com sistemas computacionais nas dimensões tecnológica, organizacional e humana, com foco na automação dos processos de negócio nas organizações, de maneira a racionalizar o uso de recursos e melhorar o processo de tomada de decisão, o controle de custos e a qualidade dos negócios realizados no âmbito organizacional.

\subsection{Sistema de Service Desk}

Este trabalho ilustra um sistema de informação de nível operacional, o qual foi desenvolvido como um trabalho da disciplina SI. O objetivo do sistema é ser um gerenciador de demandas de TI (Service Desk) no contexto de uma organização/empresa de pequeno/médio porte (entre 500 a 5000 funcionários), cujas solicitações relacionadas a TI são geradas pelas mais diversas áreas da instituição.

No trabalho SI de Service Desk, durante a fase de levantamento de requisitos, está relatado que existe uma grande a quantidade de software desenvolvido e disponível nessa área. Conforme orientados pelo professor da disciplina, os alunos pesquisaram diversas soluções e testaram algumas soluções de código aberto que encontraram disponíveis na internet, como o OcoMon [Ribeiro 2005]. Da mesma forma, descobriram vários serviços de service desk disponíveis em ambiente de nuvem, onde uma pequena empresa pode pagar apenas pelo recurso utilizado, alguns deles começando com um nível de serviço gratuito ou tendo um período de teste gratuito, e.g., Zendesk [Zendesk 2016]. Apesar de todos os programas disponíveis, que poderiam ser customizados (reúso de código) para atender aos objetivos do trabalho, os alunos consideraram que, para os fins didáticos da disciplina, seria melhor modelar e implementar um SI de Service Desk mais simples, com alguns Casos de Uso chave.

Para implementar o sistema os alunos utilizaram o ambiente de desenvolvimento em nuvem da Oracle, utilizando uma ferramenta de desenvolvimento rápido o APEX [Oracle 2015]. No APEX a aplicação é acessada por meio de um WebListener, que pode ser um servidor Web Apache. Esse servidor encaminha as requisições para o SGBD Oracle. Lá as requisições APEX são tratadas, as rotinas PL/SQL são processadas e os dados armazenados em tabelas do banco de dados. No final, a resposta ao usuário é retornada.

Os alunos escolheram este ambiente por ser de fácil implementação e possuir objetos de interface pré-definidos, que são personalizáveis, facilitando a construção rápida 
de aplicações. Este ambiente também conta com a facilidade do desenvolvimento em nuvem, realizado por meio de browser. Isto permite o desenvolvimento compartilhado por mais de uma aluno concomitantemente, além da hospedagem disponível gratuitamente, desde que voltada para desenvolvimento e demonstrações ${ }^{2}$.

Os alunos destacaram que o planejamento do software utilizando diagramas de UML, embora não diretamente transpostos para a linguagem de programação (PL/SQL), como seria o caso de construção em uma plataforma completamente orientada a objetos, proporcionou uma forma de documentar o sistema tornando-o mais facilmente compreensível aos outros desenvolvedores (alunos) da equipe. Segundo os alunos, isto facilitou a comunicação interna da equipe, tornando o processo de programação mais uniforme. Desta forma, a equipe considerou que o uso dos diagramas foi muito útil no processo. Outro detalhe que facilitou o desenvolvimento, ainda segundo os alunos, foi o fato do Oracle APEX ser orientado ao desenvolvimento por "Casos de Uso", tela por tela. Dessa forma, os alunos concluiram que os artefatos que mais auxiliaram no desenvolvimento foram os diagramas de caso de uso e o diagrama de estados. A Figura 2 mostra alguns diagramas UML confeccionados pelos alunos utilizando a ferramenta Astah [Astah 2015] para modelar o Sistema de Service Desk.

a)

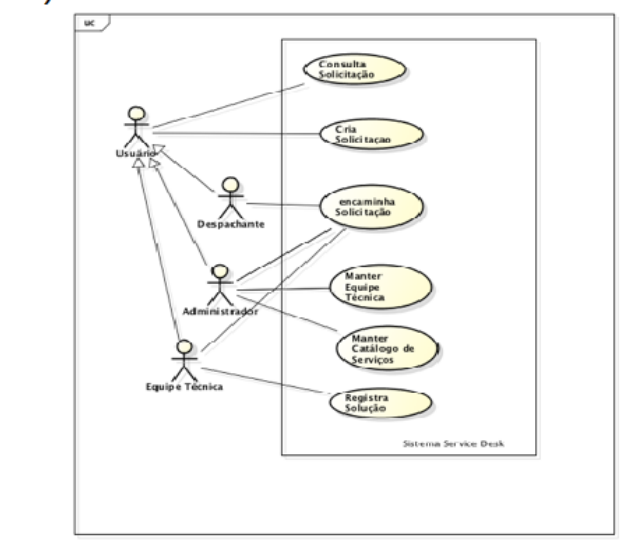

c)

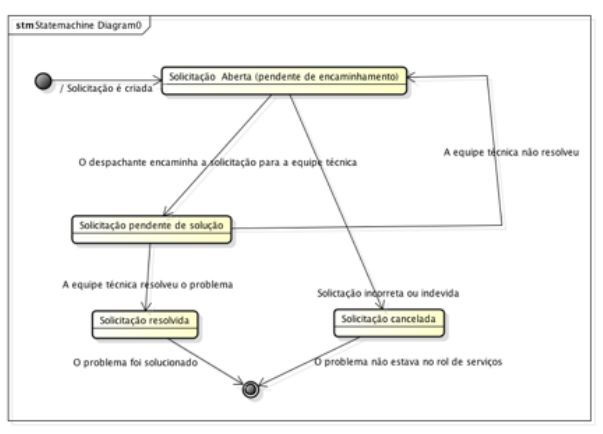

b)

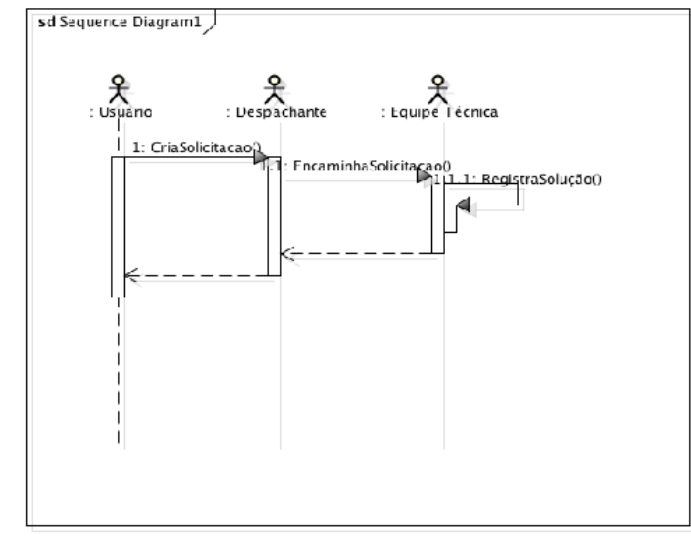

d)

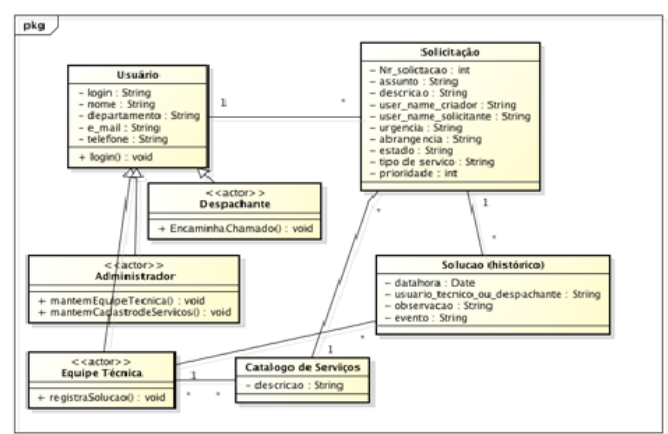

Figura 2. a) Diagrama de Casos de Uso do Sistema de Service Desk. b) Diagrama de Interações do Sistema de Service Desk. c) Diagrama de Estados do Sistema de Service Desk. d) Diagrama de Classes do Sistema de Service Desk.

\footnotetext{
${ }^{2} \mathrm{http}: / /$ apex.oracle.com
} 


\subsection{Sistema de Gerenciamento de Aplicações (SIGA)}

Dada a necessidade de monitorar as atividades de desenvolvimento de sistemas em qualquer organização que possua uma unidade de TIC, os alunos desenvolveram um Sistema de Gerenciamento de Aplicações denominado SIGA. Dentre todos os possíveis sistemas voltados para a área de TI que poderiam ser desenvolvidos, a equipe de alunos justificou esta escolha por entender que a área de TI, no que concerne ao desenvolvimento, é dispendiosa necessitando racionalização de recursos. O SIGA foi desenvolvido para auxiliar na gestão de aplicações visando maximizar os resultados da TIC através do correto aproveitamento das soluções desenvolvidas por uma organização.

O objetivo do sistema SIGA é monitorar, controlar e auditar as aplicações com base em regras de qualidade e segurança definidas pela TIC, bem como evitar o emprego desnecessário de esforço no desenvolvimento de soluções que podem já existir dentro da propria organização. Desta forma, os alunos pretendem ampliar a capacidade operacional e gerencial do departamento de TIC. O ganho operacional está em garantir maior homogeneidade e qualidade nos SI da organização, enquanto relatórios gerenciais mostram o rumo do desenvolvimento de sistemas na organização, facilitando a tomada de decisão técnica. Como o SIGA é um SI utilizado para otimizar os esforços de desenvolvimento de novas aplicações, pode ser considerado um SI para o nível de conhecimento da área de TIC de uma organização. O sistema foi desenvolvido utilizando o serviço de computação em nuvem APEX [Oracle 2015].

Inicialmente os alunos realizaram uma análise de um SI para controle de aplicações existente na Instituição XYZ visando verificar o que poderia ou não ser implementado. O passo seguinte foi o levantamento de requisitos, ocasião onde perceberam a realidade que o sistema deveria atender, tentando sempre generalizar onde possível, com foco, segundo os alunos, no tempo disponível para desenvolver e implementar todo o projeto. Segundo os alunos, esta tentativa de generalizar o sistema existente que era muito específico fez com que eles vissem um propósito maior para o sistema que dinamizaria os esforços da TIC. Os alunos perceberam que a maneira como o sistema é utilizado na Instituição XYZ é restritiva ao ponto que ela só é utilizada para fins de controle departamental, ou seja uma visão local das aplicações. Ou seja, a proposta do trabalho é dar uma visão mais global/institucional ao sistema de gerenciamento de aplicações.

Como resultado da análise concluiu-se que o SIGA propõe uma racionalização maior dos esforços da TIC ao permitir uma conversação entre os departamentos de uma organização para maximizar o uso dos sistemas departamentais, evitando desta forma um trabalho de desenvolvimento que poderia se resumir em uma simples integração de sistemas ou concessão de acesso. Os alunos ainda complementam observando que: "Mais do que Tecnologia da Informação, a realidade atual exige que se agregue a comunicação, não apenas na questão informacional, mas entre as pessoas e os setores de modo que os recursos destinados a investimentos no setor de TI sejam utilizados de forma racional, eficiente e eficaz. Foi esse o propósito do sistema que implementamos, servir como uma ferramenta para a melhoria da gestão de TI fornecendo não apenas informações mas permitindo a comunicação entre diferentes equipes para uma melhor utilização dos recursos disponíveis em uma organização."

Após o levantamento de requisitos, os alunos passaram a modelar o sistema com a criação de diagramas em notação BPMN (Figura 3) utilizando o software Bizagi 
[Bizagi 2015], Diagramas UML como o Diagrama de Estados (Figura 4) utilizando a ferramenta Astah [Astah 2015], e o Diagrama de Entidade-Relacionamento (Figura 5) para modelar o banco de dados do SIGA. Durante a modelagem os alunos testemunharam que a confecção dos diagramas são sempre trabalhosos, porém que somente após fazê-los é que se torna evidente sua importância. Segundo os alunos: "Durante o processo de modelagem percebe-se o quanto cada diagrama e modelo acaba por revelar novos requisitos e casos de uso em que não se pensa inicialmente. Com absoluta certeza pode-se afirmar que esse processo evita uma série de retrabalhos que podem consumir ainda mais tempo na execução do projeto do que seria gasto com uma modelagem bem executada."

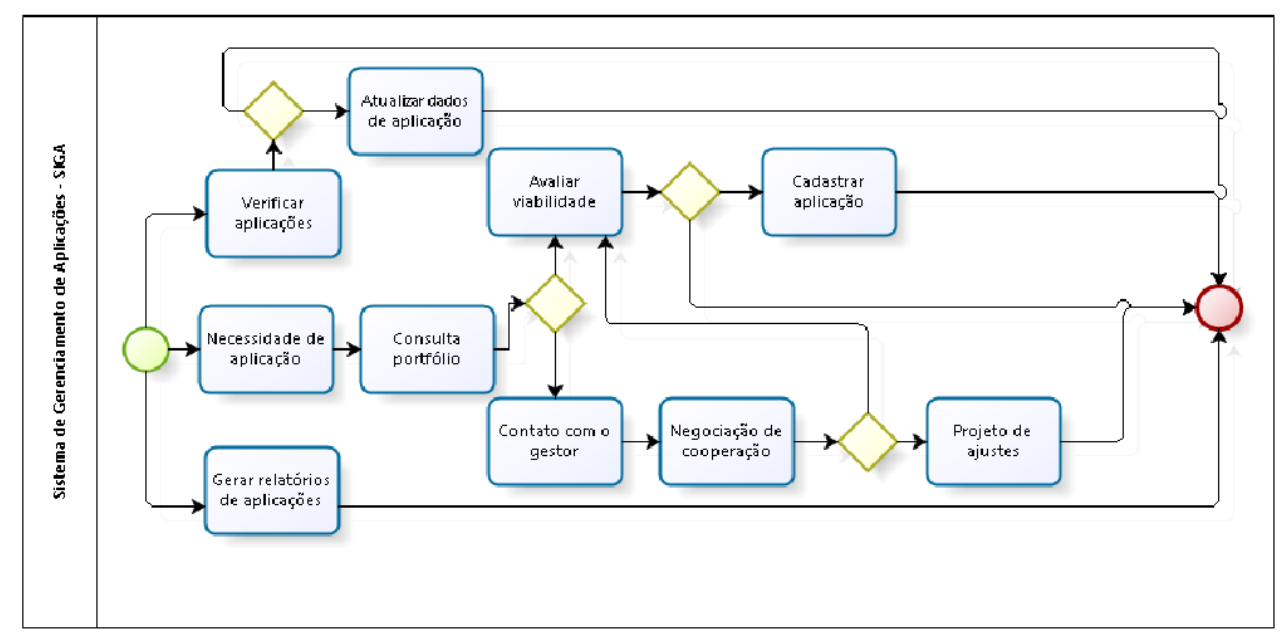

Figura 3. Mapeamento de processos de negócios do SIGA.

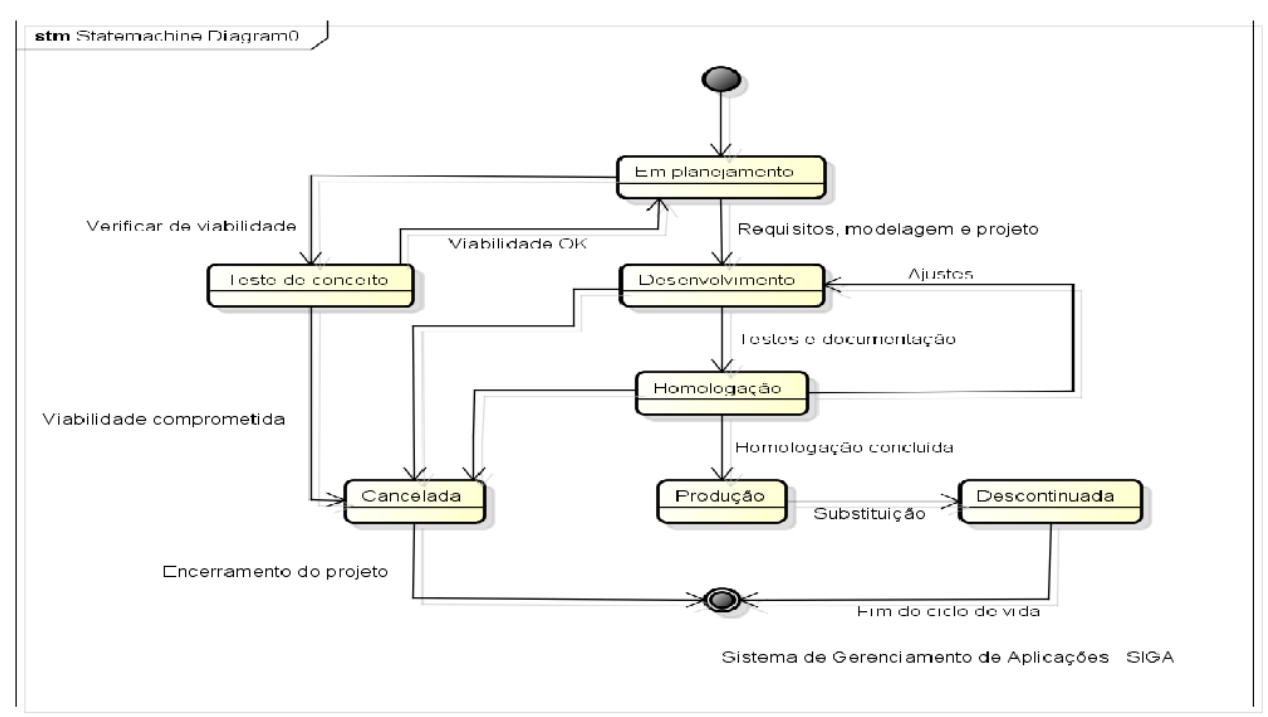

Figura 4. Diagrama de estados do SIGA.

\subsection{Módulo de Controle de Suprimentos de Impressão (MCSI)}

Neste trabalho os alunos implementaram um sistema de informação que pode ser classificado como de nível gerencial aproveitando um sistema de controle de estoque de toners 


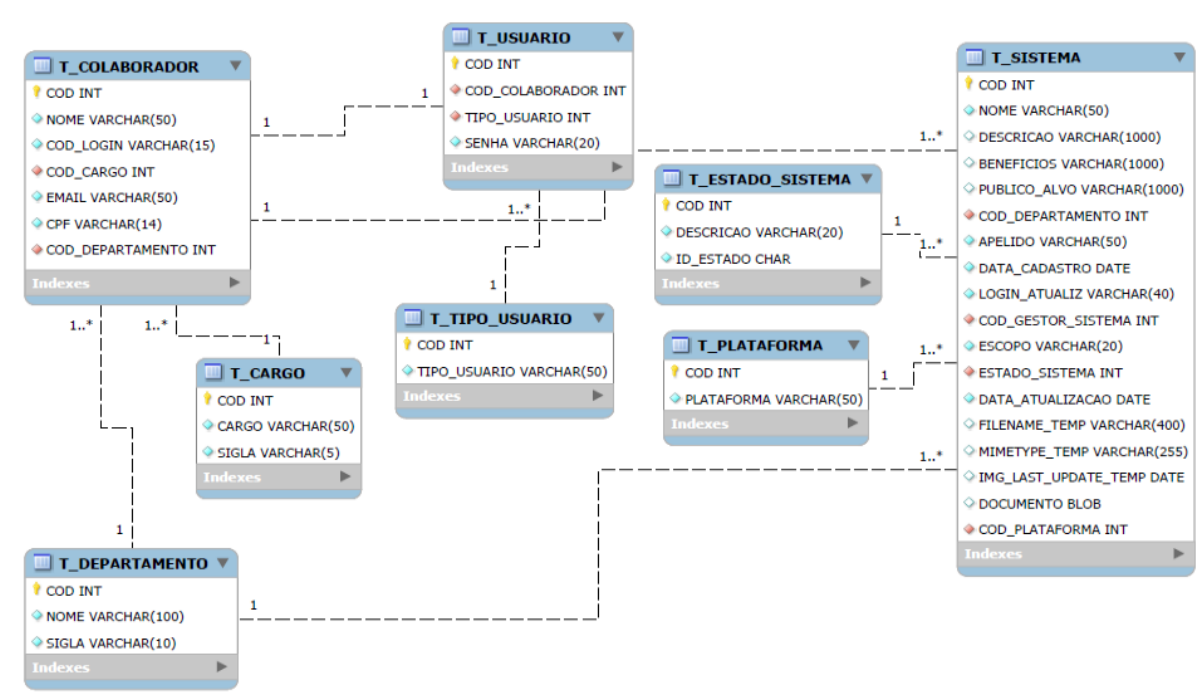

Figura 5. Diagrama Entidade-Relacionamento do SIGA.

e cartuchos de impressoras já existente na Organização ABC. O módulo que eles desenvolveram acopla-se ao sistema existente, de maneira a utilizar os seus dados.

Inicialmente os alunos observaram que na Organização $\mathrm{ABC}$ existe um sistema Web de controle de estoques de materiais de informática, operando em nível transacional. Este sistema gera relatórios das movimentações para o nível gerencial. Verificaram que a principal função do sistema é o controle da movimentação de entrada e saída de cartuchos e toners destinados a suprir o parque de impressoras distribuído nos mais diversos setores da referida organização. Verificaram também que este sistema não facilitava a tomada de decisão a nível gerencial na empresa, sendo necessário para tal a adaptação de vários relatórios gerenciais em ferramenta de planilha externa ao sistema o que nem sempre fornece a agilidade, a precisão e a facilidade de entendimento necessárias para o referido nível organizacional, causando eventuais perdas de recursos decorrentes de aplicações equivocadas.

$\mathrm{Na}$ fase de levantamento de requisitos os alunos observaram a utilização do sistema atual de controle de estoque por parte dos operadores da Seção de Informática (SIN) e por meio de entrevistas com o Diretor de TIC da empresa e com o Gerente da SIN, buscando levantar as funcionalidades necessárias ou desejadas para o novo módulo do sistema. Os principais requisitos levantados foram:

- O módulo deve gerar comparativos anuais de gastos por impressora em suprimentos em forma de tabelas e gráficos;

- De acordo com o comparativo de consumo ao longo dos anos, o módulo deve estimar o consumo para os anos seguintes em termos quantitativos de cartuchos e toners;

- Com base no preço médio e tendo em conta a variação anual destes preços, bem como os índices de inflação previstos no mercado financeiro, o módulo deve projetar os gastos com suprimentos para os anos seguintes; e

- Analisar quais os modelos de impressoras apresentam o melhor rendimento, bem como apontar os menos eficientes neste quesito, visando descartes ou 
substituições.

$\mathrm{Na}$ sequência, os alunos modelaram o processo de acordo com o diagrama da Figura 6. O sistema foi implementado utilizando a tecnologia de computação em nuvem, por meio do serviço de hospedagem da Amazon Web Services (AWS) [Amazon 2015], no nível de uso gratuito. O nível de uso gratuito está disponível para novos clientes da AWS por até um ano, desde que não ultrapasse o limite de recursos previsto neste nível de uso, o que é mais do que suficientes para as necessidades do trabalho da disciplina. Por exemplo, para este trabalho os alunos usaram o Elastic Compute Cloud (EC2) com o Sistema Operacional Linux/Unix, servidor Web Apache e aplicações escritas na linguagem PHP, que no nível gratuito disponibiliza até 750 horas por mês de instâncias, 30 GB de volume de armazenamento e dois milhões de operações de entrada e saída. Além disso, o Relational Database Service (RDS) que permite 750 horas por mês de instâncias para execução do mySQL, 20 GB de armazenamento de dados e 10 milhões de operações de entrada e saída.
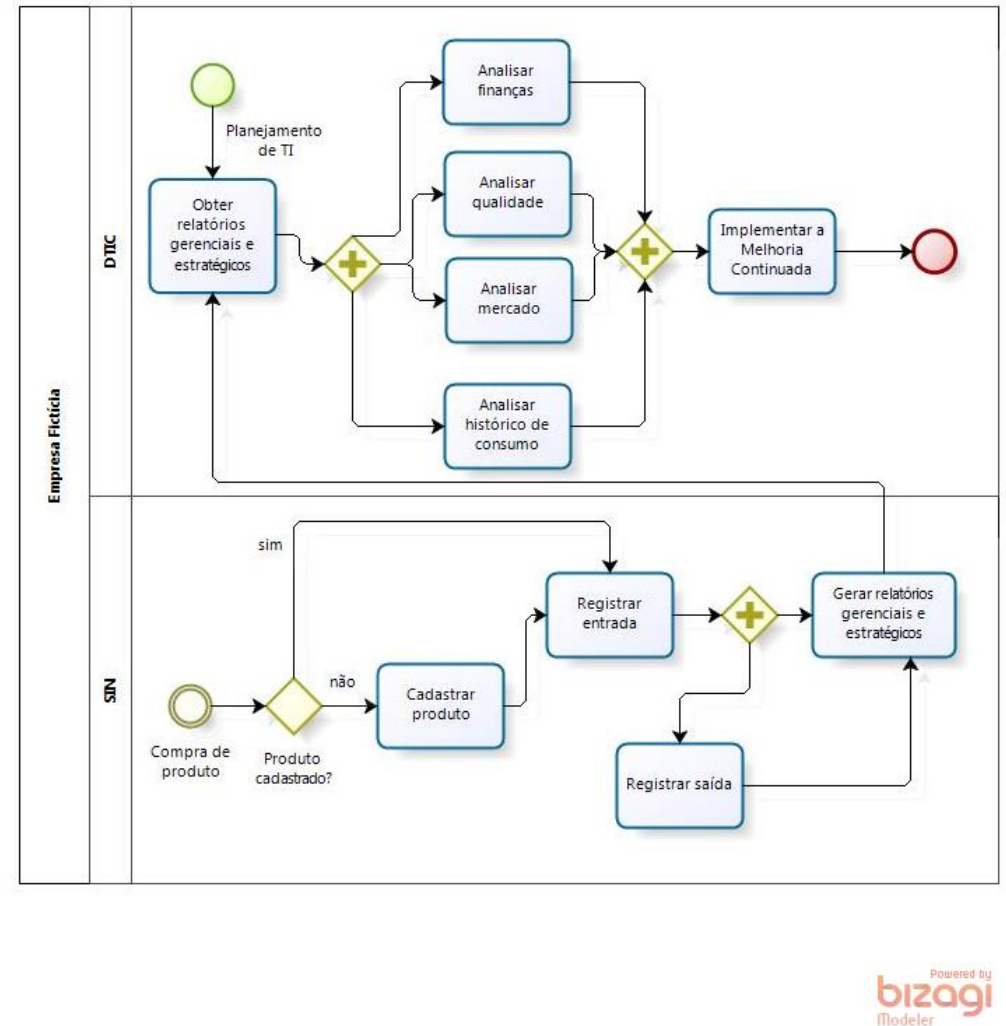

Figura 6. Diagrama de processos do MCSI.

Como resultado, o sistema implementado permite a visualização de relatórios e gráficos úteis para o nível gerencial. Um dos gráficos deste módulo, Figura 7 a), facilita a leitura do consumo geral de cartuchos na empresa, permitindo aos gestores fazer uma análise comparativa do custo/benefício da aquisição de cada marca ou modelo de cartucho, orientando futuras aquisições de impressoras que apresentem suprimentos com melhor custo/benefício. O gráfico de barras, Figura 7 b), permite visualizar o valor anual dispendido com suprimentos de TIC da organização ABC. O MCSI também emite relatórios textuais. A tela da Figura 7 c), relatório 1, mostra o gasto realizado com suprimentos 
de impressão no ano de 2014. Observe que as mesmas informações do relatório 1 foram usadas para gerar o gráfico da Figura 7 a), mas com uma visão em percentual do gasto para cada item. A tela da Figura 7 d) mostra o consumo no ano de 2014 dos suprimentos de impressão que estavam no almoxarifado, por divisão da organização ABC.

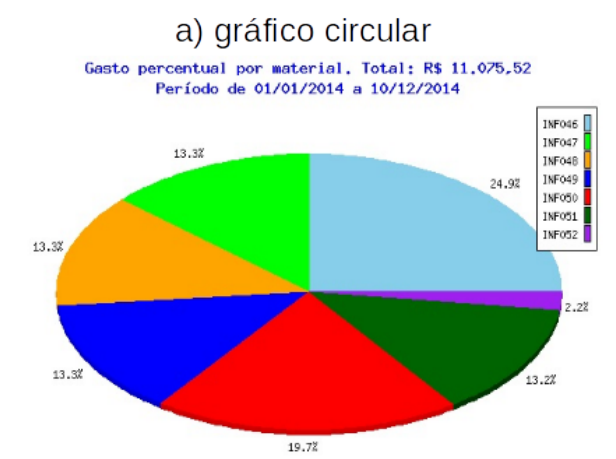

c) relatório 1

Relatório de Gastos De 01/01/2014 a 10/12/2014

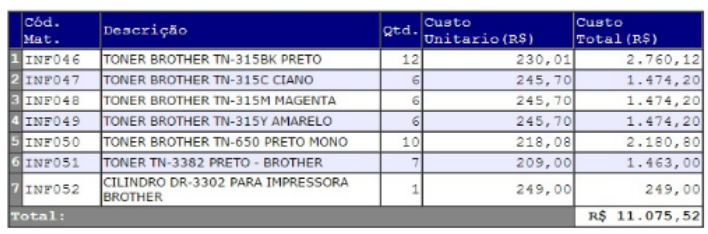

b) gráfico de barras

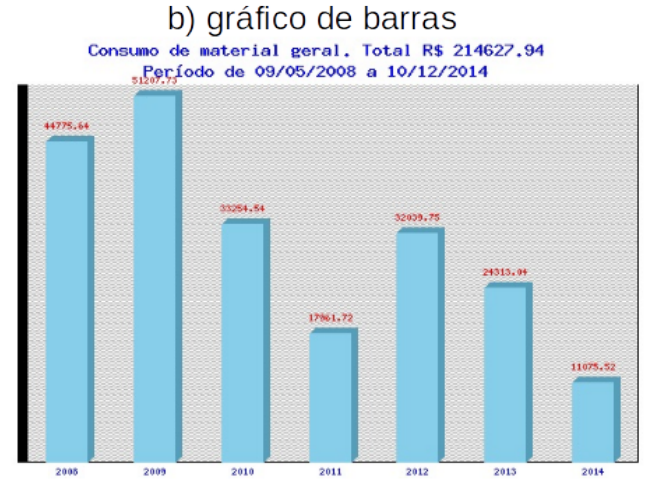

d) relatório 2

Relatório de Consumo Interno De 01/01/2014 a 10/12/2014

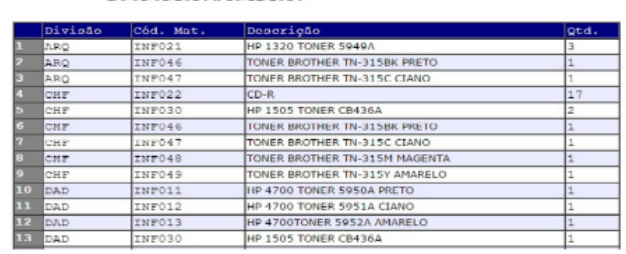

Figura 7. Gráficos e telas gerado pelo MCSI que facilitam a interpretação do consumo de suprimentos de informática na organização. a) Gráfico circular com a percentagem de consumo de cada item de suprimentos de impressão. b) Gráfico de barras com material de consumo. c) Tela com relatório do consumo de cada item do suprimentos de impressão. d) Tela com relatório de consumo de itens de informática

\subsection{Sistema de Estudo de Viabilidade para Projetos de Serviços de Telecomunicações}

O estudo de viabilidade é o primeiro documento que formaliza a interação entre uma empresa que presta serviços de telecomunicações e o cliente em potencial. O estudo de viabilidade fornece informações sobre a solicitação do cliente para verificar a viabilidade técnica de se prover o serviço, o custo para sua implementação, a melhor solução para o serviço, entre outros aspectos importantes. Todas estas informações são compiladas para se montar uma proposta comercial elaborada pela Gerência de Vendas e pela Gerência de Engenharia de Pré-Venda.

Apesar do estudo de viabilidade comercial ser comum em muitas empresas, uma vez que ele permite prever e monitorar a capacidade de ser prover um produto ou serviço, reduzir custos e planejar ações de mercado, o artigo do trabalho da disciplina menciona que é difícil achar soluções de SI comerciais dependendo dos produtos e serviços fornecidos. Da mesma forma, justifica que devido a especificidade dos produtos e serviços da área de telecomunicações, cada empresa implementa o seu sistema customizados para suas necessidades. Ou seja, dada estas condições, optou-se por desenvolver um sistema de informação de Estudo de Viabilidade para Projetos de Serviços de Telecomunicações. 
O sistema implementado faz parte de um projeto a ser implantado por uma empresa real. Com o objetivo de manter a segurança e a confidencialidade dos parâmetros das informações de caráter restrito, estas foram substituídas sem perda da integridade das funcionalidades do sistema implementado para o trabalho da disciplina.

A Figura 8 mostra o mapeamento atual do processo utilizado pela empresa. Ele é baseado em uma planilha eletrônica enviada por e-mail pelo gerente de contas ao engenheiro de pré-venda. A resposta acontece da mesma forma, enviando planilhas eletrônicas por e-mail.

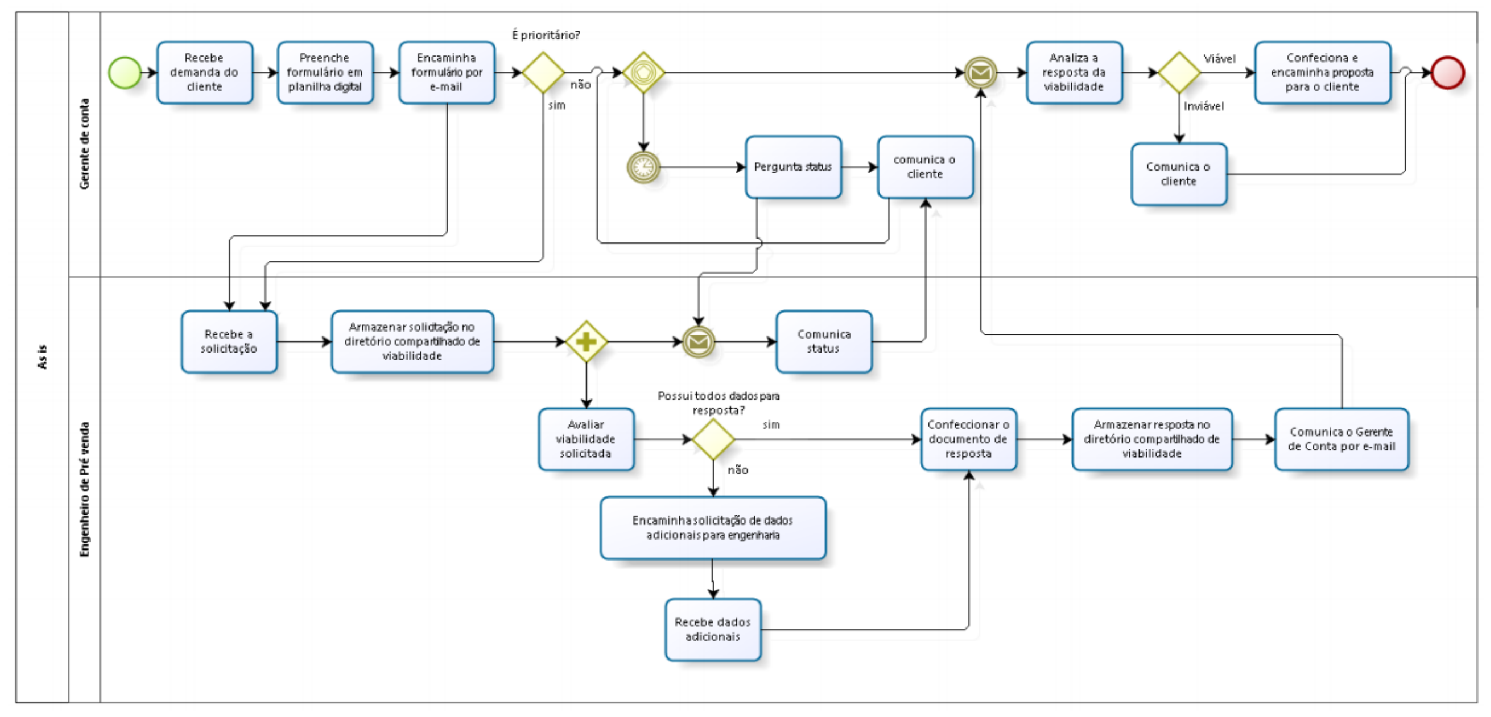

Figura 8. Mapeamento do Processo para estudo de viabilidade de projetos de serviços de telecomunicações (AS-IS).

O sistema proposto é uma aplicação baseada em Web que permitirá o controle, armazenamento, análise e confecção do estudo de viabilidade pelos diretores da empresa, conforme o processo apresentado na Figura 9.

O sistema foi implementado usando a banco de dados MySQL e scripts PHP. Os alunos usaram a ferramenta Astah [Astah 2015] para modelar o sistema. A Figura 10 mostra o diagrama de estado da instância de uma classe denominada estudo de viabilidade do sistema.

Como trabalhos futuros, as seguintes funcionalidades foram propostas:

- possibilidade do sistema emitir relatórios por meio de gráficos;

- integração entre o CEP e o endereço do cliente;

- integração entre o endereço e latitude/longitude por meio da API Geocoding do Google;

- visualização de um mapa por meio da API JavaScript do GoogleMaps; e

- carregamento de solicitações por meio de uma planilha eletrônica.

No curto espaço de tempo disponível de dezesseis semanas, o protótipo apresentado implementava a parte principal do sistema, no que foi avaliado positivamente. 


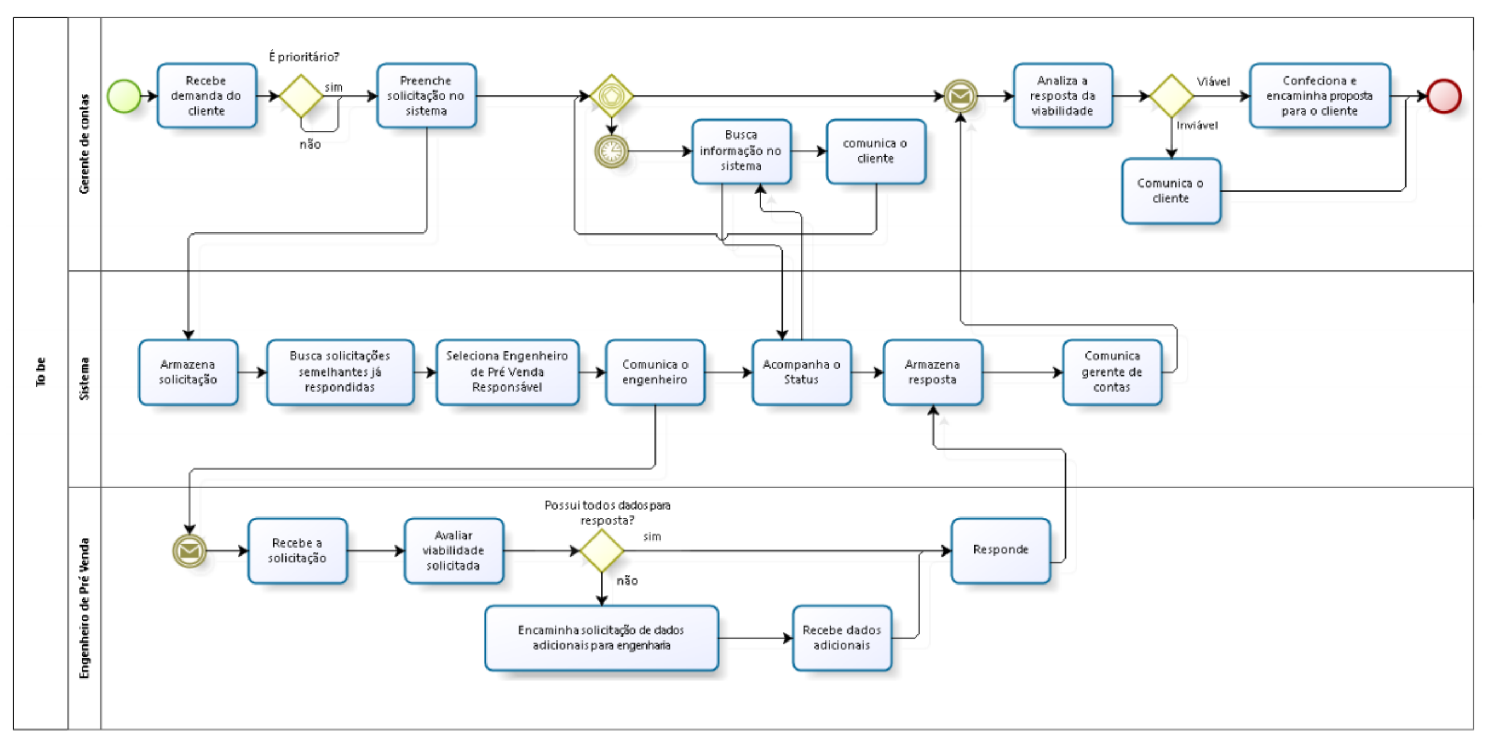

Figura 9. Mapeamento do Processo para estudo de viabilidade de projetos de serviços de telecomunicações (TO-BE).

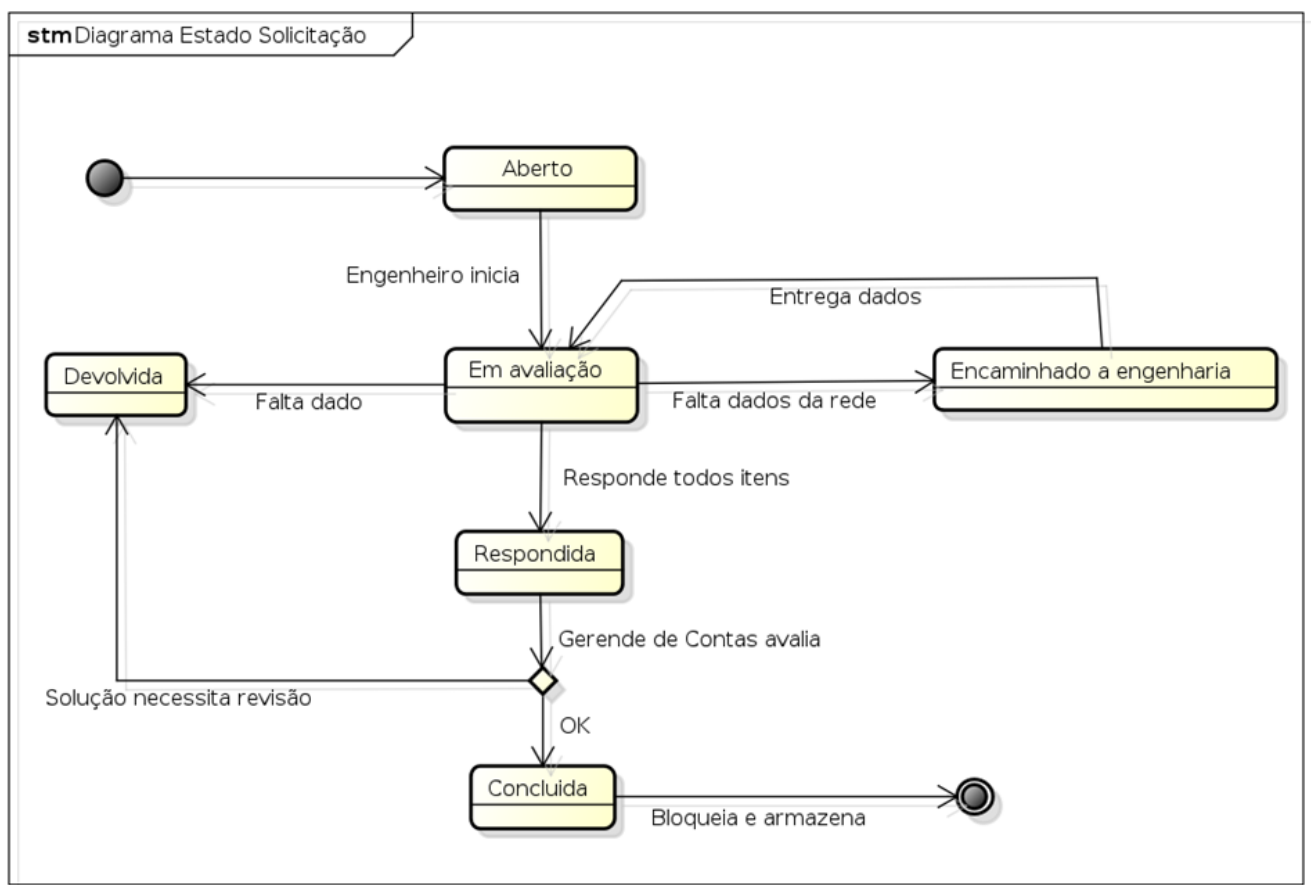

Figura 10. Diagrama de Estado do Estudo de Viabilidade.

\section{Levantamento do Perfil dos Alunos}

Para levantar o perfil da turma de SI do turno noturno, foi aplicado um questionário, cuja resposta era voluntária. O objetivo foi comprovar dados já conhecidos informalmente, de que alunos do turno noturno na sua maioria exercem atividades laborais no turno diurno e, no caso dos alunos da área de computação, que muitos trabalham na área de TIC. Este 
questionário continuou a ser aplicado nas turmas subsequentes para verificar que o perfil se manteve ao longo da amostragem.

a) Divisão por faixa etária

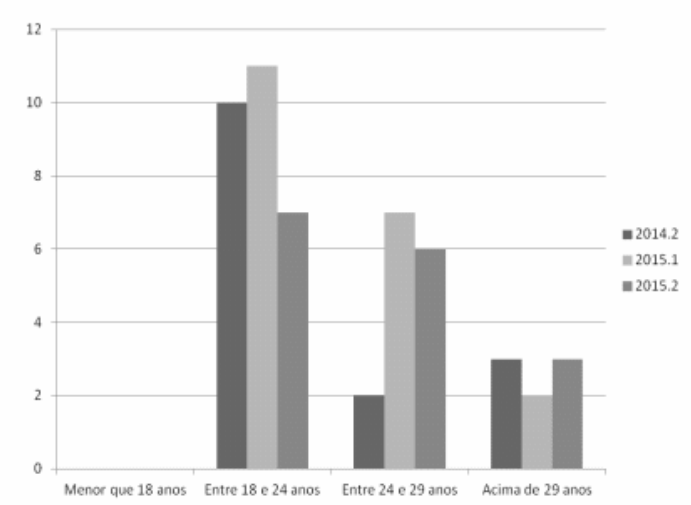

b) Divisão por cursos

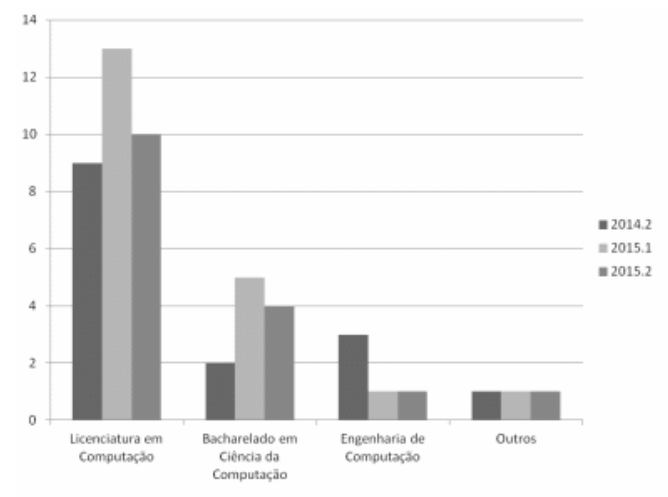

d) Divisão por setor

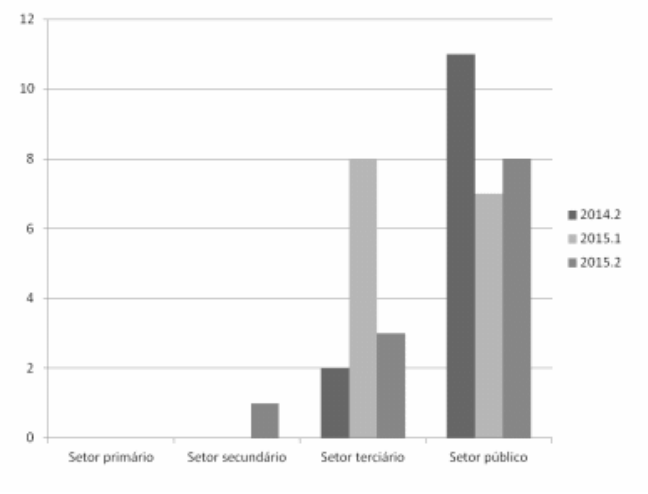

c) Divisão por atividade remunerada

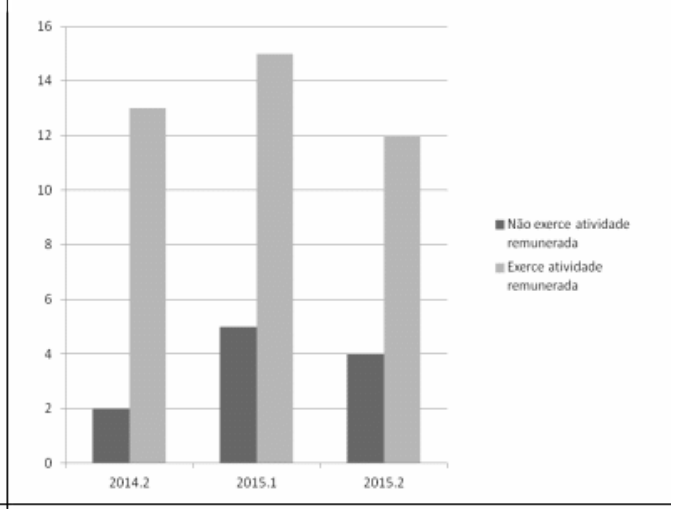

e) Divisão entre TIC/Outros

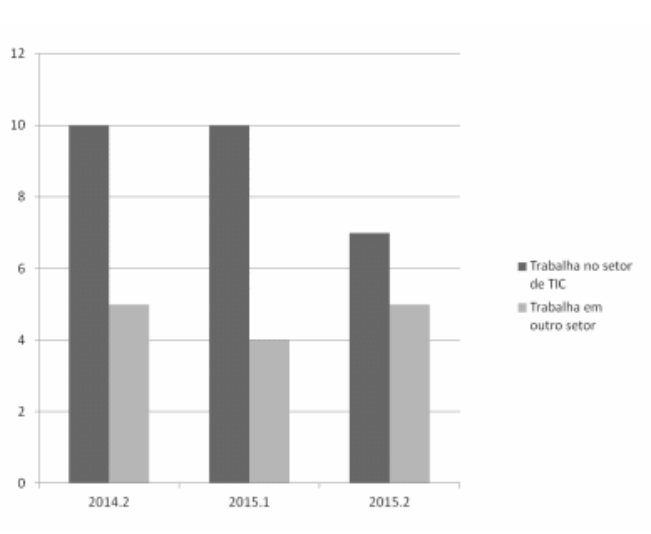

Figura 11. a) Gráfico com a divisão dos alunos do turno noturno por faixa etária; b) Gráfico com a quantidade de alunos por curso na disciplina SI do turno noturno; c) Gráfico mostrando que quase $80 \%$ dos alunos de SI do turno noturno exercem atividade remunerada; e d) Graf́ico mostrando que, dos alunos de SI do turno noturno que exercem atividade remunerada, quase todos são do setor de serviços, sendo que mais da metade trabalham no setor público. e) Gráfico que mostra que $65 \%$ dos alunos de SI do turno noturno que exercem atividade remunerada, trabalham no setor de TIC da sua organização. 
Neste levantamento foi possível constatar que, apesar do curso ser noturno, boa parte dos alunos se encontram na faixa de idade universitária (18 a 24 anos), conforme o gráfico da Figura 11 a). O gráfico da Figura 11 b) mostra a classificaçãos dos alunos da turma por cursos, onde se percebe uma predominância dos alunos de licenciatura em computação. O gráfico da Figura $11 \mathrm{c}$ ) mostra que os alunos que cursam a disciplina no turno noturno o fazem porque exercem atividade diurna remunerada. O gráfico da Figura $11 \mathrm{~d}$ ) mostra que quase a totalidade dos alunos da disciplina SI do turno noturno que exercem atividade remunerada o fazem no setor terciário da economia, sendo que a grande maioria trabalha no setor público. Esta característica reflete o perfil da cidade de Brasília, cidade jovem criada para ser a capital da federação que ainda não conseguiu diminuir sua dependência econômica do governo federal e distrital.

Nas instituições em que estes alunos trabalham, todos possuem SI automatizados e utilizam estes sistemas nas suas atividades laborais. O gráfico da Figura11 e) mostra que a maioria dos alunos, não é apenas usuário da TIC, mas trabalha no setor de TIC. Este perfil corrobora a decisão de enfatizar a implementação de SI que resolvam, na prática, os problemas que os alunos enfrentam ou enfrentarão como profissionais da área.

\section{Questionário de Avaliação}

Para se avaliar a percepção dos alunos em relação ao conteúdo da disciplina de SI, foi aplicado no final do segundo semestre de 2014, período em que inicialmente se aplicou a abordagem deste artigo, um questionário de avaliação, cuja resposta era voluntária. A turma no qual foi aplicado o questionário contava com 23 alunos, dos quais 17 foram aprovados. Dos 23 alunos da turma, 15 responderam ao questionário. Dos alunos que não responderam o questionário, encontram-se 6 alunos que não obtiveram aprovação por terem faltado mais de $25 \%$ das aulas. Em levantamento informal realizado, verificou-se que alguns alunos deixaram de frequentar as aulas por motivos pessoais ou por alta carga de trabalho. De qualquer forma, seria interessante apurar as causas com uma metodologia mais formal, descartar possíveis tendências não reveladas pela presente pesquisa. O questionário foi mandado para todos os alunos por meio do site de EaD Moodle [Moodle 2016] com mensagem de alerta por e-mail.

O questionário procurou levantar a opinião dos alunos em relação ao conteúdo da disciplina e a metodologia de ensino utilizada. Para esta análise utilizou-se a escala de Likert [Likert 1932], cujas respostas poderiam variar de 1 a 5, onde 1 corresponde a discordo totalmente e 5 concordo totalmente, de forma que o aluno poderia marcar o número 3 , caso não soubesse responder. A Tabela 2 sumariza os resultados do questionário em relação ao conteúdo da disciplina de SI. As respostas 1 e 2, discordo totalmente e discordo, respectivamente, foram agrupadas no universo dos que discordaram da afirmação. As respostas 4 e 5, concordo e concordo totalmente, respectivamente, foram agrupadas no universo dos que concordaram com a afirmação. A resposta 3 pode ser classificada como uma resposta indiferente ou de indecisão em relação a afirmação.

Na Pergunta 2.1 a maioria dos alunos concordou com a importância dos conhecimentos da disciplina SI na sua formação profissional, apenas um aluno não concordou nem discordou. Este aluno era do curso de Engenharia de Computação, cujo curso tem uma ênfase maior no conhecimento a nível de hardware e sofware básico e computação embarcada e que talvez, neste caso, se precise trabalhar melhor a necessidade do co- 
nhecimento de sistemas de mais alto nível para sua formação profissional, uma vez que o mesmo concordou que os conhecimentos transmitidos foram úteis (Pergunta 2.2), em consonância com os demais alunos que responderam o questionário.

Setenta e três por cento das respostas da Pergunta 2.3 concordam que SI é uma disciplina que motivou concluir o curso, o que mostra o acerto desta abordagem no ensino da disciplina de SI para alunos de cursos de Computação.

De uma maneira geral, as respostas sobre o conteúdo programático da disciplina de SI, conforme se verifica na Tabela 2, Perguntas 2.4 a 2.6, indicam que o conteúdo utilizado está no caminho certo. Ou seja, a disciplina de SI deve abordar as futuras necessidades do profissional de TIC como gestor de negócios de uma organização genérica e como gestor de negócios de uma organização de TIC, capacitando os alunos a compreender os problemas de um departamento de TIC de uma organização e buscar soluções de SI que tragam vantagens competitivas a uma organização, empregando a TIC na sua solução.

As respostas as perguntas 2.7 e 2.8 mostram que o objetivo de valorizar a necessidade de se criar valor pelo uso da informação, criando espaço para a inovação, incentivando o aluno a pensar em como projetar, criar ou adapatar SI para este fim foi plenamente atingido.

A Pergunta 2.9 do questionário teve o objetivo de sondar a respeito de se abordar SI utilizados na área de ensino, uma vez que a maioria dos alunos é de Licenciatura em Computação. A princípio, alunos de licenciatura deveriam se interessar por SI voltados para a gestão escolar, SI para auxiliar o professor em suas disciplinas e SI para auxiliar no aprendizado dos alunos. No entanto, dos nove alunos de licenciatura que responderam ao questionário, três discordaram, um foi indiferente e cinco concordaram. Ou seja, percebese que os alunos da licenciatura estão divididos em relação a se abordar SI voltados para a gestão ou auxílio ao ensino. Em vista deste resultado, questionou-se informalmente as suas causas, e os alunos relataram que o seu maior interesse não é atuar especificamente na área de ensino/educação de computação, mas sim como um profissional de computação.

Já em relação ao uso de SI que visem ao empreendedorismo, Pergunta 2.10, com a criação e o gerenciamento de novas empresas, apenas $40 \%$ das respostas foram positivas. Uma interpretação para este resultado é que estes alunos, mesmo já tendo uma colocação no serviço público, gostariam de ter a oportunidade de também se tornar empreendedores do setor de TIC.

No campo sugestões do questionário, alguns alunos opinaram para que todos da turma usassem o Apex, o ambiente de nuvem da Oracle, uma vez que existem alunos que ainda não dominam completamente o desenvolvimento e a implementação de sistemas e isto resolveria o problema de heterogeneidade da turma. Dois alunos também solicitaram que a disciplina tenha um enfoque ainda mais prático do que ela já tem. Isto mostra a importância de se usar uma abordagem prática no ensino da disciplina de SI.

Este questionário constata algo evidente, que esta abordagem no ensino de SI é mais adequada para os alunos do curso noturno da área de Computação. O que surpreende, é a escassez de trabalhos que tratam deste tema. Uma vez comprovado este resultado, seria redundante continuar aplicando o questionário às turmas subsequentes. 
Tabela 2. Resultados das perguntas referentes ao conteúdo da disciplina SI

\begin{tabular}{|l|c|c|c|}
\hline Perguntas & \% Concordo & \% Indeciso & \% Discordo \\
\hline $\begin{array}{l}\text { 2.1 A disciplina SI é importante para a minha formação profis- } \\
\text { sional. }\end{array}$ & 93,3 & 6,7 & 0 \\
\hline 2.2 A disciplina SI agregou conhecimentos úteis. & 100 & 0 & 0 \\
\hline $\begin{array}{l}\text { 2.3 A disciplina SI me motivou a concluir o curso de graduação } \\
\text { que estou fazendo. }\end{array}$ & 73,3 & 26,7 & 0 \\
\hline $\begin{array}{l}\text { 2.4 A disciplina SI precisa abordar, em termos de conteúdo mi- } \\
\text { nistrado, as minhas futuras necessidades como gestor de negócios } \\
\text { de uma organização. }\end{array}$ & 86,6 & 6,7 & 6,7 \\
\hline $\begin{array}{l}\text { 2.5 A disciplina SI precisa abordar, em termos de conteúdo } \\
\text { ministrado, as minhas futuras necessidades como profissional } \\
\text { da área de TIC, seja como executor ou gestor de TIC de uma } \\
\text { organizaçãoo. }\end{array}$ & 86,6 & 13,4 & 0 \\
\hline $\begin{array}{l}\text { 2.6 A disciplina SI precisa abordar, em termos de conteúdo mi- } \\
\text { nistrado, as minhas futuras necessidades como profissional da } \\
\text { área de TIC, como gestor de negócios de uma organização cuja } \\
\text { atividade fim é TIC. }\end{array}$ & 80 & 20 & 0 \\
\hline $\begin{array}{l}\text { 2.7 A disciplina SI deve capacitar o aluno para achar soluções de } \\
\text { SI que tragam vantagem competitiva à uma organização. }\end{array}$ & 93,3 & 6,7 & 0 \\
\hline $\begin{array}{l}\text { 2.8 A disciplina SI deve capacitar o aluno a compreender os pro- } \\
\text { blemas das organizações e como TIC pode ajudar a solucioná-las. }\end{array}$ & 100 & 0 & \\
\hline $\begin{array}{l}\text { 2.9 A disciplina SI também deve abordar Sistemas de Informação } \\
\text { para a atividade fim de ensino, uma vez que alunos de licenciatura } \\
\text { em computação podem frequentá-la. }\end{array}$ & 46,7 & 20 & 33,3 \\
\hline $\begin{array}{l}\text { 2.10 A disciplina SI deve se concentrar mais no aspecto organiza- } \\
\text { cional, focando na criação e gerenciamento de empresas. }\end{array}$ & 40 & 26,7 & 33,3 \\
\hline
\end{tabular}

\section{Conclusões e Trabalhos Futuros}

O resultado da pesquisa de opinião feito com os alunos da disciplina corroboram os objetivos propostos pelo uso de uma abordagem teórico/prática de ensino da disciplina de SI. A disciplina de SI deve dar uma ênfase maior nas futuras necessidades do profissional de TIC como gestor de negócios de uma organização que possui um setor de TIC e ele precisará estar capacitado a gerenciar, entendendo o negócio da organização e contribuindo efetivamente com a missão da organização.

A disciplina de SI também deve preparar os alunos para serem gestores de negócios de uma organização de TIC, ou seja, organizações cuja atividade fim é a TIC. Por fim, a disciplina deve capacitar os alunos a compreender os problemas da área de TIC de uma organização e buscar soluções de SI que tragam vantagens competitivas a uma organização, desenvolvendo e implementando uma solução adequada.

Em suma, os pontos altos da abordagem proposta neste artigo é a ênfase em SI que atendam as futuras necessidades do profissional de TIC e o uso de trabalhos práticos para atingir este objetivo. Como ponto fraco, cumpre observar que esta disciplina é ofertada a partir do quarto período do curso, fase em que os alunos ainda não cursaram disciplinas cujos conceitos são usado nos trabalhos de SI. Por exemplo, como muitos alunos não cursaram a disciplina Banco de Dados (BD), é preciso que o professor adiante noções de banco de dados relacionais. O ideal é que esta disciplina seja ofertada na terça parte final do curso. Com o propósito de atender estes requisitos, nos novos currículos dos cursos de Licenciatura em Computação e Bacharelado em Ciência da Computação que acabaram de ser aprovados, a disciplina de SI terá como pré-requisito a disciplina BD e é ofertada 
mais tarde.

Como trabalhos futuros, pretende-se investigar o porquê da escassez de trabalhos referentes ao tema deste artigo, qual seja "Ensino da disciplina de SI para estudantes de computação". Em seguida, realizar uma pesquisa com os docentes da Disciplina de SI de cursos de Computação do país, para colher opiniões sobre esta abordagem metodológica, a fim de aperfeiçoá-la. Pretende-se também utilizar técnicas da metodologia de ensino de aprendizagem baseado em problemas (PBL). Para isto, problemas concretos de TIC da UnB ou dos órgãos governamentais sediados em Brasília serão levantados e a participação dos alunos para a sua resolução será negociada com seus responsáveis. Com isto, esperase que os alunos vivenciem as reais dificuldades em viabilizar SI junto a um cliente ou usuário de TIC reais, tendo que negociar com os mesmos a limitação do escopo do sistema e o levantamento de seus requisitos. A modelagem e implementação do sistema, atividades que já são realizados na disciplina continuam, mas enriquecidas pelo método PBL.

\section{References}

[Amazon 2015] Amazon (2015). Amazon Web Services. Disponível em http://aws.amazon.com/, consultado em fevereiro de 2015.

[Astah 2015] Astah (2015). Astah - UML Modeler. Disponível em http://astah.net/editions/community, consultado em fevereiro de 2015.

[Audit and Association 2015] Audit, I. I. S. and Association, C. (2015). COBIT Control Objectives for Information and Related Technology. Disponível em http://www.isaca.org/cobit, consultado em fevereiro de 2015.

[Barbieri 2011] Barbieri, C. (2011). BI2 - Business Intelligence: Modelagem e Qualidade. Elsevier.

[Bizagi 2015] Bizagi (2015). Bizagi - BPMN Modeler. Disponível em http://www.bizagi.com/, consultado em fevereiro de 2015.

[Buyya et al. 2009] Buyya, R. et al. (2009). Cloud computing and emerging IT platforms: Vision, hype, and reality for delivering computing as the 5th utility. Future Generation Computer Systems, 25(6):599-616.

[CNPQ 2015] CNPQ (2015). Tabelas de áreas se conhecimento. "http: / / www . cnpq . br/documents/10157/186158/TabelasAreasdoConhecimento. pdf ". Acessado em: 08/Fev/2016.

[Digiampietri et al. 2012] Digiampietri, L. A. et al. (2012). Complementando o aprendizado em programação: Experiências no curso de sistemas de informação da USP. In Anais do VIII Simpósio Brasileiro de Sistemas de Informação, pages 779-790, São Paulo, SP.

[França et al. 2015] França, R. S. et al. (2015). Explorando o pensamento computacional no ensino médio: do design à avaliação de jogos digitais. In XIII Workshop sobre Educação em Informática.

[Gestal 2014] Gestal, P. R. E.; Barros, R. M. (2014). Proposta de um simulador para auxiliar no processo de ensino do Scrum. In Anais do X Simpósio Brasileiro de Sistemas de Informação, pages 723-736, Londrina, PR. 
[Grijpink 2015] Grijpink, F.; Alan Lau, A. V. J. (2015). Demystifying the hackathon. "http://www.mckinsey.com/insights/innovation/ demystifying_the_hackathon". Accessado em: 08/Fev/2016.

[Group 2015] Group, O. O. M. (2015). Business Process Model and Notation. Disponível em http://www.bpmn.org/, consultado em fevereiro de 2015.

[Kroll 2003] Kroll, P.; Kruchten, P. B. G. (2003). The Rational Unified Process Made Easy: A Practitioner's Guide to the RUP: A Practitioner's Guide to the RUP. AddisonWesley Professional; 1 edition.

[Laudon 2015] Laudon, K.; Laudon, J. (2015). Management Information Systems: Managing the Digital Firm. Prentice Hall, New Jersey.

[Likert 1932] Likert, R. (1932). A technique for the measurement of attitudes. Archives of Psychology, 22(140):55.

[M. Stair 2006] M. Stair, R. M.; Reynolds, G. W. (2006). Principles of Information Systems: a managerial approach. Thomson Learning.

[Microsoft 2008] Microsoft (2008). Microsoft Operations Framework v4.0. Disponível em http://www.microsoft.com, consultado em fevereiro de 2015.

[Moodle 2016] Moodle (2016). Moodle - open-source learning platform. "https: / / moodle.org". Acessado em: 21/Mai/2016.

[Nogueira et al. 2013] Nogueira, D. N. et al. (2013). Utilizando meta-design para customização de conteúdo em um portal de jogos educativos. In XII Simpósio Brasileiro sobre Fatores Humanos em Sistemas Computacionais.

[Nunamaker 1990] Nunamaker, J. F. Jr.; Chen, M. P. T. D. M. (1990). Systems development in information system research. Journal of Management Information Systems, 7(3):89106.

[OGC 2011] OGC (2011). Introduction to the ITIL Service Life Cicle. TSO.

[Oracle 2015] Oracle (2015). Oracle Application Express. Disponível em https://apex.oracle.com/i/index.html, consultado em fevereiro de 2015.

[OWASP 2008] OWASP (2008). The Open Web Application Security Project. Disponível em https://www.owasp.org/, consultado em fevereiro de 2015.

[Pavani 2011] Pavani, O. Jr.; Scuglia, R. (2011). Mapeamento e Gestão por Processos BPM. M. Books do Brasil Editora Ltda.

[Podeswa 2009] Podeswa, H. (2009). UML For The IT Business Analyst. Cengage Learning PTR; 2 edition.

[Rainer 2008] Rainer, R. K.; Turban, E. (2008). Introduction to Information Systems: Support and Transforming Business. Wiley.

[Ralha 2006] Ralha, C. G.; Fernandes, J. H. C. (2006). Ensino de sistemas de informação para cursos de graduação em computação: Uma experiência integradora e inovadora. In Anais do XIV Workshop sobre Educação em Computação, pages 88-97, Campo Grande, MS. 
[Rebouças et al. 2010] Rebouças, A. D. D. S. et al. (2010). Aprendendo a ensinar programação combinando jogos e Python. In XXI Simpósio Brasileiro de Informática na Educação.

[Ribeiro 2005] Ribeiro, F. (2005). Ocomon - monitor de ocorrências e inventário de equipamentos de informática. "http://ocomonphp. sourceforge.net/". Acessado em: 21/Mai/2016.

[Sampaio 2007] Sampaio, R. F.; Mancini, M. (2007). Estudos de revisão sistemática: um guia para síntese criteriosa da evidência científica. Revista Brasileira de Fisioterapia, 11(1):83-89.

[SBC 1999] SBC (1999). Currículo de referência da sociedade brasileira de computação para cursos de graduação em computação e informática. In http://www.sb.org.br. SBC.

[Scholar 2016] Scholar, G. (2016). Google scholar - web search engine. "https: // scholar.google.com". Acessado em: 20/Jun/2016.

[Silva Filho 2007] Silva Filho, R.L. L.; Motejunas, O. P. H. O. L. M. B. C. M. (2007). A evasão no ensino superior brasileiro. Cadernos de Pesquisa, 37(132):641-659.

[Suzuki et al. 2011] Suzuki, C. C. C. et al. (2011). A utilização de jogos em treinamentos e ações de institucionalização de processos. In X Simpósio Brasileiro de Qualidade de Software.

[The Economist 2015] The Economist (2015). The rise of hackathons: What the hack? "http://www. economist.com/news/business/21679457-techindustry-tradition-has-entered-corporate-mainstreamwhat-hack". Accessado em: 08/Fev/2016.

[Weill 2004] Weill, P.; Ross, J. W. (2004). IT Governance - How Top Performers Manage IT Decision Rights for Superior Results. Harvard Business School.

[Zendesk 2016] Zendesk (2016). Conhecendo seu zendesk. "http://www . zendesk.com.br/recursos/conhecendo-seu-zendesk/". Acessado em: 21/Mai/2016. 